\title{
SCHOOLING AND LABOR MARKET CONSEQUENCES OF SCHOOL CONSTRUCTION IN INDONESIA: \\ EVIDENCE FROM AN UNUSUAL POLICY EXPERIMENT
}

\author{
Esther Duflo \\ Working Paper 7860 \\ http://www.nber.org/papers/w7860 \\ NATIONAL BUREAU OF ECONOMIC RESEARCH \\ 1050 Massachusetts Avenue \\ Cambridge, MA 02138 \\ August 2000
}

The views expressed herein are those of the author and not necessarily those of the National Bureau of Economic Research.

(C) 2000 by Esther Duflo. All rights reserved. Short sections of text, not to exceed two paragraphs, may be quoted without explicit permission provided that full credit, including (C) notice, is given to the source. 
Schooling and Labor Market Consequences of School Construction in Indonesia: Evidence from an Unusual Policy Experiment

Esther Duflo

NBER Working Paper No. 7860

August 2000

JEL No. I2, J31, O15, O22

\begin{abstract}
Between 1973 and 1978, the Indonesian Government constructed over 61,000 primary schools throughout the country. This is one of the largest school construction programs on record. I evaluate the effect of this program on education and wages by combining differences across regions in the number of schools constructed with differences across cohorts induced by the timing of the program. The estimates suggest that the construction of primary schools led to an increase in education and earnings. Children ages 2 to 6 in 1974 received 0.12 to 0.19 more years of education for each school constructed per 1,000 children in their region of birth. Using the variations in schooling generated by this policy as instrumental variables for the impact of education on wages generates estimates of economic returns to education ranging from 6.8 percent to 10.6 percent.
\end{abstract}

\author{
Esther Duflo \\ Department of Economics \\ MIT, E52-252G \\ 50 Memorial Drive \\ Cambridge, MA 02142 \\ and NBER \\ eduflo@mit.edu
}




\title{
Schooling and Labor Market Consequences of School Construction in Indonesia: Evidence from an Unusual Policy Experiment
}

\author{
Esther Duflo*
}

The question of whether investment in infrastructure increases human capital and reduces poverty has long been a concern to development economists and policymakers. For example, availability of schooling infrastructure has been shown to be positively correlated with completed schooling or enrollment by Nancy Birdsall (1985) in urban Brazil, Dennis DeTray (1988) and Lee A. Lillard and Robert J. Willis (1994) in Malaysia, Victor Lavy (1996) in Ghana, and Anne Case and Angus Deaton (1996) in South Africa. The principal methodological problem with these studies is that schools are not randomly allocated across communities. In education systems relying on local financing, more affluent communities can afford to build more schools. Children in these communities are likely to be more educated and earn more as adults. Alternatively, in centralized education systems, government resources may be allocated to regions that are lagging behind (as was the case with school construction in Indonesia in the 1970's). As a 
result, education and wages may be lower in the regions that have more government schools. The ideal experiment to estimate the effects of building schools would be to allocate schools randomly to some communities and not to others, and then to compare education and earnings across communities. In the absence of evidence from such an experiment, it is necessary to rely on exogenous natural variations in combination with statistical modeling strategies.

This paper exploits a dramatic change in policy to evaluate the effect of building schools on education and earnings in Indonesia. In 1973, the Indonesian government launched a major school construction program, the Sekolah Dasar INPRES program. Between 1973-74 and 197879 more than 61,000 primary school buildings - an average of two schools per 1,000 children aged 5 to 14 in 1971 - were built. The government's goal was to increase enrollment rates among children aged 7 to 12 from 69 percent in 1973 to 85 percent by 1978. In 1978, the enrollment rate reached 84 percent for males and 82 percent for females (World Bank (1990a)). Indonesia's primary schooling expansion is cited by the World Bank as "one of the most successful cases of large-scale school expansion on record" (World Bank (1990a)). This program represented a drastic change in Indonesian policy. Prior to 1973, capital expenditures in the education sector were very low (Ruth Daroesman (1971)) and enrollment rates seemed to be declining in the early 1970's (Daroesman (1971), Ward Heneveld (1978)).

The identification strategy in this paper uses the fact that exposure to the school construction program varied by region of birth and date of birth. Substantial variations existed in program intensity across regions, due to the government's efforts to allocate more schools to regions where initial enrollment was low. Therefore, the education of individuals who were young enough to be in school when the program was launched should be higher than the education of older individuals in all regions, but the difference should be larger in the regions that received more schools. I use a difference in differences estimator that controls for (additive) systematic variation of education both across regions and across cohorts. Only the combination of the two variations is treated as exogenous. Similar strategies are often used in the public finance literature to evaluate the effects of public policies. Mark R. Rosenzweig and Kenneth I. Wolpin (1988a) first proposed using fixed-effects methods for evaluating the impact of public programs in developing countries, which were applied in the Indonesian context by Mark Pitt, Rosenzweig, and Donna Gibbons (1993) and Paul Gertler and John W. Molyneaux (1994). This schooling reform is particularly well suited for fixed-effects methods because the variation in inputs comes from a well defined 
reform. This makes it possible to test an implication of the identification assumption, namely that the combination of the variation over time and across regions is exogenous. I show that among early cohorts, who did not benefit from the program because they were too old to attend primary school when it started (individuals 12 or older in 1974), the increase in educational attainment from one cohort to another is not correlated with the number of INPRES schools per capita built from 1973 to 1978. The same strategy is used to estimate the impact of this program on 1995 wages. Finally, I use this exogenous source of variation in education to estimate the impact of years of schooling on wages.

The question of whether an increase in educational attainment causes an increase in income levels is a basic concern for development economists. A large body of literature exists on returns to education in developing countries (see George Psacharopoulos $(1973,1981,1985,1994)$ ) for surveys). Estimated returns are, in general, larger in developing countries than in industrialized countries. Surprisingly, however, very little effort has been made to estimate returns to education using only exogenous variations in schooling. The bias in estimates that treat an individual's education level as exogenous is likely to be important in developing countries. In particular, liquidity constraints and family or community background are likely to influence both education and earnings. Jere R. Behrman's (1990) assessment of the existing literature is that most standard estimates of returns to education in developing countries are likely to overstate them. John Strauss and Duncan Thomas (1995) review several additional articles and suggest that the evidence is inconclusive and deserves further study. However, it is difficult to find sources of exogenous variation in education. Most factors that influence education are also likely to have indirect effects on income. This is clearly true in the case of family background variables (e.g., assets and parental education), which are often used as instruments or included in the set of instruments on the grounds that they are good predictors of education. If the concern is that unobserved family and community background characteristics are sources of bias in OLS estimates of returns to education, observed family and community variables should be entered as covariates in the wage equation and are not likely to be valid instruments. This is often also true of other potential instruments. For example, birth order has been shown to affect education. But it also affects health, which in turn affects income. ${ }^{1}$ Proximity of parents residence to educational facilities has been used as an instrument for college education in the United States (David Card (1993); Thomas J. Kane and Cecilia E. Rouse (1995)), and years of secondary 
education in the Philippines (John Maluccio (1998)). ${ }^{2}$ These studies suffer from the problem outlined above. Depending on how schools are allocated, schooling and wages might be lower or higher in households living near or far away from a school, even if there is no causal effect of the proximity of a school on education. This paper exploits the exogenous variation in education created by the INPRES program to construct instrumental variables estimates of the effect of education on wages.

Using a large cross-section of men born between 1950 and 1972 from the 1995 intercensal survey of Indonesia (SUPAS), I linked an adult's education and wages with district-level data on the number of new schools built between 1973-74 and 1978-79 in his region of birth. The exogenous variables (and the instruments in the wage equation) are interactions between dummy variables indicating the age of the individual in 1974 and the intensity of the program in his region of birth between 1973 and 1978. Similar strategies have been used to estimate the effect of school quality on returns to education (Card and Anne Krueger (1992)), the effect of teen fertility on educational and labor market outcomes (Joshua Angrist and W.N. Evans (1996)), and the effect of college education on earnings (Card and Thomas Lemieux (1998)).

The remainder of this paper is organized as follows. In section I, I describe the INPRES program and the data. In section II, I present the identification strategy and discuss the identification assumption using a simple model of endogenous schooling. In section III, I present the estimated impact of the program on education. Section IV is devoted to the estimation of the effect of the program on wages. In section V, I estimate economic returns to education. In section VI, I combine the estimates of the program effect on wages with detailed data on the cost of education in Indonesia to present a tentative cost-benefit analysis of the program. Section VII concludes the paper.

\section{The Program}

\section{A. Data}

The 1995 intercensal survey of Indonesia is a sample of over 200,000 households. It is conducted every ten years by the Central Bureau of Statistics of Indonesia. Basic data is collected on each individual in the household. In this study, I focus on men born between 1950 and 1972 (which ensures that the individuals in the sample have completed their education). Summary statistics 
for this sample are presented in table 1, panel A. There are 152,989 individuals in the sample, with an average level of 7.98 years of completed education (6 years of education correspond to graduation from primary school). The SUPAS collects data on last month's wage for people who are working for pay. From this, I calculate an hourly wage by dividing the monthly wage by the number of hours worked during the month. I estimate the effects of the program on education using the complete sample, but the wage equation is estimated using the sample of individuals who work for a wage, which has only 60,633 individuals (sample selection issues are examined below).

The SUPAS asks in which district the individual was born. I use this information to match the individual survey data with district-level data (pertaining to the situation in the district in the 1970's) collected from various sources: Ministry of Education and Culture, presidential instructions published by the Bappenas (the Planning Agency), and published results from the 1971 census. ${ }^{3}$ District-level descriptive statistics are presented in table 1, panel B.

\section{B. The Sekolah Dasar INPRES Program}

Since 1973, the "presidential instructions" (INPRES) have been the main centrally controlled fiscal mechanism determining spatial redistribution of the aggregate gains to Indonesia from the oil boom (Martin Ravallion (1988)). Over the years, the scheme has evolved into a complex system of grants for various purposes, such as building schools, health clinics, and roads, as well as more routine government spending.

The Sekolah Dasar INPRES program was one of the first INPRES programs and the largest at the time it was launched (in 1973-74). During the first Indonesian five-year plan, the emphasis was on basic infrastructure and sectoral development. Agriculture, industry/mining, and communication absorbed 70 percent of the development budget (Hal Hill (1996)). At the outset of the second five-year plan, which emphasized the need for equity, changing priorities were evident. Regional development became an important item (absorbing 15 percent of the budget). The Sekolah Dasar INPRES program represented, in turn, 12 percent of the regional development budget in 1973 and 28 percent in 1979 (for comparison, health expenditures represented only 3.4 percent of the budget for regional development in 1973 (and 5.5 percent in 1979)). ${ }^{4}$ The budget itself, thanks to the oil boom, expanded very rapidly during this period. Real expenditures more than doubled between 1973 and 1980 while the share of oil in government revenues 
grew from 25 percent in 1971 to 48 percent in 1974 and peaked at 62 percent in 1981 . Due to the combination of these two factors (change in priority and increase in revenues), the Sekolah Dasar INPRES program became extremely important.

Basic data about the program is presented in table 1, panel B. Between 1973-74 and 1978-79, 61,807 new buildings were constructed. ${ }^{5}$ This represented approximately 222 new schools (and 666 new teachers) per district or over one school per every 500 children aged 5 to 14 in 1971 . This amounted to double the number of existing school buildings. However, since the INPRES schools were smaller than most existing schools (three teachers), the increase in the number of teachers was only 43 percent. ${ }^{6}$ Prior to 1973 , in contrast, very few schools were constructed. There was a complete ban on the recruitment of new civil servants. Some newly trained teachers could not find employment (Daroesman (1971)).

Once an INPRES school was established, the central government recruited the teachers and paid their salaries (each school was designed for three teachers and 120 pupils). The minimum requirement to be a primary school teacher was an upper secondary school degree, generally obtained in a special training school. In 1971, 71 percent of the primary school teachers met this qualification, while 29 percent were underqualified. An effort to train more teachers paralleled the INPRES program (World Bank (1990b)).

The program was designed explicitly to target children who had not previously been enrolled in school, and a separate budget was designed for the rehabilitation of existing run-down buildings (Heneveld (1978)). The distribution of funds is described in detailed governmental instructions (the "presidential instructions": (Bappenas 1973, 1974, 1975, 1976, 1977, 1978)). All schools were constructed identically. The instructions were explicit about the allocation rule. In 1973-74 and 1974-75, the number of schools to be constructed in each district was proportional to the number of children of primary school age not enrolled in school in 1972. From 1975-76 on, the rule was spelled out slightly differently but had similar implications: the number of schools to be constructed was proportional to the number of new pupils to be accommodated between 1972 and 1978 in the region to satisfy the target enrollment rate of 85 percent in 1978. More schools were allocated to the transmigration regions. ${ }^{7}$ The final allocation was decided by planners in the Ministry of Education and Culture, with the approval of the Department of Finance and the Bappenas, the administration responsible for the final implementation of the program. Funds were then sent through the governor's office to the local administrations, who 
supervised the actual construction. The instructions listed the exact number of schools to be constructed in each district (kabupaten/kotamadya).

I use this planned number in my analysis, rather than the actual number of schools constructed, which is not available. In 1983, the Ministry of Education and Culture conducted a survey of the implementation of the program from 1973 to 1983 . According to this study, the actual number of schools constructed matched the plans until 1980. Some discrepancy occurs thereafter. The Ministry of Education and Culture has also published data on the number of schools operating in 1973-74 and 1978-79. This data suggests that the actual increase in the number of functioning schools was lower than the number of schools constructed between 197374 and 1977-78 under the INPRES program. One reason is that prior to 1973, several schools were frequently operating in the same building (as soon as a school had more than one class per grade, it became two schools, with separate head-teachers and administrative status). School buildings in urban areas could operate in as many as four shifts a day (Daroesman (1971)). It is quite possible that some new buildings were used to reduce overcrowding in the old ones. Consistent with this, the average increase in the number of teachers implied by the allocation of INPRES schools is very close to the increase in the actual number of teachers recorded by the Ministry of Education.

Using this data, I first checked whether the actual allocation decided upon by the Ministry of Education corresponds to the stated allocation rule. I used the Ministry data on the number of children enrolled in school in the school year 1973-1974 to construct an estimate of rate of nonenrollment in 1973-74 among children aged 5 to 14 years old. ${ }^{8}$ Table 2 presents the results of a regression of the logarithm of the number of INPRES schools constructed in each region on the logarithm of the nonenrollment rate and the logarithm of the number of children. The actual rule would predict that both coefficients should be close to one. The logarithm of the number of schools built in each region between $1973-74$ and 1978-79 is positively correlated with the logarithm of the number of children and with the logarithm of one minus the enrollment rate. ${ }^{9}$ A substantial part of the variation between regions is explained by these two factors alone: the R-squared is 0.78 . The coefficient of the nonenrollment rate is, however, not equal to one. This might be explained by measurement error in the enrollment measure, and by the fact that I do not use the actual formula, which was nonlinear (regions that had an enrollment rate of 85 percent in 1972 were not supposed to get any schools). Finally, the implementation of such a 
massive program in a country as large and heterogenous as Indonesia was bound to involve some deviation from the general rule.

\section{Identification Strategy}

\section{A. Sources of Variation}

The date of birth and the region of birth jointly determine an individual's exposure to the program. A child born in 1962 or before was 12 or older in 1974, when the first INPRES schools were constructed. Indonesian children normally attend primary school between the ages of 7 and 12. Thus, a child aged 12 or older in 1974 normally did not benefit from the program, since he should have left primary school before the school year 1974-75, when the first INPRES schools (built in 1973-74) were opened. Grade repetition and delayed school entry could lead a few of these children to benefit from the program for their last year in school (which would lead to downward bias in the estimation if they are mistakenly considered as nontreated). ${ }^{10}$ However, the exposure of children aged 12 or older in 1974 is very limited. According to the 1993 Indonesian Family Life Survey (IFLS) data set (conducted in 1993 by RAND and the Demographic Institute at the University of Indonesia), less than 3 percent of these children were still in primary school in 1974 (the schools were opened in the second half of 1974). A child born in 1968 was 6 in 1974 and 11 in 1979. He was exposed to the first wave of construction while he was of primary school age but only partly to the next waves. A child born in 1972 was fully exposed. In summary, children 12 or older in 1974 were not exposed to the program and for younger children the exposure is decreasing with their age in 1974. As a result, the effect of the program should be 0 for children 12 or older in 1974 and increasing for younger children.

The intensity of the program varied across regions. The region of birth is highly correlated with the region of education. 91.5 percent of the children in the IFLS sample, were still living in the district they were born in at age 12. Migration introduces measurement error, which leads to downward bias in the estimation of the program effect. However, endogenous migration could bias estimates of program effects obtained by comparing outcomes according to the individual's region of education (Rosenzweig and Wolpin (1988b)). Some families might have moved between the birth of a child and his education period to benefit from the program. Region of birth, on the

other hand, is not endogenous with respect to the program, since all individuals in the sample 
were born before the program was started. Therefore, the parents could not have moved to the high program regions before the birth of the child to benefit from the program. ${ }^{11}$

Thus, the basic idea behind the identification strategy can be illustrated using simple twoby-two tables. In table 3 , I present results that illustrate the identification strategy and a test of an implication of the identifying assumption. These results are imprecise, due to the fact that only a small part of the available information is used. They are provided as an illustration of the identification strategy. This table shows means of education and wages for different cohorts and program levels. ${ }^{12}$ In table 1, I indicate the program intensity in both types of regions. In high program regions an average of 2.44 schools per 1,000 children were built; in low program regions, an average of 1.54 schools per 1,000 children were built. The difference was 0.90 school per 1,000 children. In table 3, panel A, I present the main experiment. I compare the educational attainment and the wages of individuals who had little or no exposure to the program (they were 12 to 17 in 1974) to those of individuals who were exposed all the time they were in primary school (they were 2 to 6 in 1974), in both types of regions. The program provision that more schools would be built in lower enrollment regions is reflected in the differences between the education in low and high program regions. In both cohorts, the average educational attainment and wages in regions that received fewer schools are higher than in regions that received more schools. In both types of regions, average educational attainment increased over time. However, it increased more in regions that received more schools. The difference in these differences can be interpreted as the causal effect of the program, under the assumption that, in the absence of the program, the increase in educational attainment would not have been systematically different in low and high program regions. An individual young enough, born in a high program region, received on average 0.12 more years of education, and the logarithm of his wage in 1995 was 0.026 higher. These differences in differences are not significantly different from 0 . This simple estimator suggests that one school per 1,000 children contributed to increase education by 0.13 years (0.12 divided by 0.90 ) and wages by 0.029 for children aged 2 to 6 when the program was initiated. The Wald estimate (a simple — but imprecise - instrumental variables estimator) of returns to education is the ratio of these two estimates.

This difference in differences estimator is comparable to the fixed-effect procedure proposed for the evaluation of social programs in developing countries. ${ }^{13}$ As Strauss and Thomas (1995) 
point out in their assessment of the approach adopted by these papers, the identification assumption should not be taken for granted: the pattern of increase in education could vary systematically across regions. Moreover, the simple differences (the differences in education across cohorts and between regions) are large. This makes the difference in differences sensitive to assumptions about functional form (Bruce D.Meyer (1995), James J. Heckman (1996)). In particular, if the increase in education was negatively correlated with initial levels, this pattern would be observed in the data even if the program had no effect.

Therefore, an interesting aspect of this experiment is that an implication of the identification assumption can be tested. Individuals aged 12 or older in 1974 were not exposed to the program. Therefore, in this age group, the increase in education between cohorts should not differ systematically across regions. This control experiment exploits the presence of multiple control groups formed by the successive cohorts not exposed to the program (see Heckman and V. Joseph Hotz (1989) and Paul R. Rosenbaum (1987)).

In table 3, panel B, I present this control experiment. I consider a cohort aged 18 to 24 in 1974 and a cohort aged 12 to 17 in 1974. The estimated differences in differences are very close to 0 . These results provide some suggestive evidence that the differences in differences are not driven by inappropriate identification assumptions but the differences in differences are imprecisely estimated. In panel B, for example, the differences in differences are insignificantly different from 0 but also from the differences in differences in panel $\mathrm{A}$. The remainder of this paper will elaborate this strategy to lead to more convincing results.

\section{B. Conceptual Framework}

In this subsection, I use a simple version of the model of endogenous schooling developed in Card (1995), who draws on Gary Becker (1967). I extend it to take into account the general equilibrium implications of the program, since such a large program could have affected the returns to education. ${ }^{14}$

I write an individual's utility in the form $U(w, S)=\ln w(S)-h(S)$, where $h(S)$ is the cost of schooling function and $w(S)$ is the income of an individual with schooling $S$. Following Card, the marginal cost of schooling is written $h^{\prime}(S)=r_{i j k}+\phi S$. I assume that returns to schooling are linear ${ }^{15}$

$$
y_{i j k}=\ln w_{i j k}=a_{i j k}+b_{i j k} S,
$$


where $y_{i j k}$ is the logarithm of the wage of an individual $i$, born in region $j$, in cohort $k$.

Individuals maximize expected utility. Optimal choice of schooling implies

$$
S_{i j k}=\frac{E_{k} b_{i j k}-r_{i j k}}{\phi}
$$

where $E_{k} b_{i j k}$ denotes the expectation of future returns to education at a time when the individual makes his schooling decision. Heterogeneity is modeled additively: $b_{i j k}=b_{j k}+\nu_{i}$ and $r_{i j k}=$ $r_{j k}+\omega_{i}$, where $b_{j k}$ is the average returns to education for cohort $k$, in region $j$, and $\nu_{i}$ is the individual deviation from the regional average.

To capture the most important modifications induced by the program, the cost of education is modeled as a linear function of the number of primary schools per capita $\left(Z_{j k}\right)$ and other regional characteristics not affected by the program $\left(\mu_{j k}\right)$ :

$$
r_{j k}=\alpha_{1} Z_{j k}+\mu_{j k}
$$

Returns to education are in turn affected by the quality of education and the supply and demand for skills. I write them as a linear function of the average education in the region $\left(S_{j}\right)$, the average education in the country $(\bar{S})$, the quality of schooling in the region at the time people received their education $\left(q_{j k}\right)$, and regional economic conditions which will determine the demand for skills in the region $\left(v_{j}\right):^{16}$

$$
b_{j k}=2 \beta_{1} S_{j}+2 \beta_{2} \bar{S}+\beta_{3} q_{j k}+v_{j} .
$$

The program directly affected the cost of education and indirectly its returns, due to potential changes in school quality and to general equilibrium effects of an increase in education on the price of skills. Assume (realistically) that the generations educated before the program did not anticipate it when choosing their education level $\left(E_{0} Z_{j k}=Z_{j 0}\right.$ and $\left.E_{0} q_{j k}=q_{j 0}\right)$. Then the increase in average education caused a reduction in actual returns to education of everybody in the labor market (equation (4)), but it only affected the expected returns of the cohorts exposed to the program. Consider the average education of an old cohort, not exposed to the program, denoted 0, and a younger cohort of age $k$ in 1974, denoted $k$. Assuming (to simplify notation), that there are only two cohorts and that they have the same size, ${ }^{17} \mathrm{I}$ can compute the expressions for these averages implied by the rational expectation equilibrium of this model. ${ }^{18}$

The difference between these two averages takes the following form:

$$
S_{j k}-S_{j 0}=\pi_{0}+\pi_{1}\left(Z_{j k}-Z_{j 0}\right)+\pi_{2}\left(q_{j k}-q_{j 0}\right)+\xi_{j}
$$


where $\pi_{0}$ is a constant term that incorporates the changes in the expected average education in the country, $\pi_{1}=-\frac{\alpha_{1}}{\phi-\beta_{1}}, \pi_{2}=\frac{\beta_{3}}{\phi-\beta_{1}}$, and $\xi_{j}$ reflects changes in all other factors affecting the returns and costs of education.

The increase in the number of primary schools per capita available between any cohort and the oldest cohort in the sample is a function of the total number of INPRES schools per capita constructed in the region, denoted $P_{j}$, and the exposure of this cohort to the program, denoted $e_{k}$; which is equal to 0 for nonexposed cohorts ( $k$ greater than 13$)$, and to 1 for a fully exposed $\operatorname{cohort}\left(Z_{j k}-Z_{j O}=e_{k} P_{j}\right)$. The quality of schooling is not directly observed. I can capture the possibility that the program affected the quality of education by writing the change in the quality of schooling as: $q_{j k}-q_{j 0}=e_{k}\left(\lambda P_{j}+\rho_{j}\right)$. I can, therefore, write the previous expression as

$$
S_{j k}-S_{j 0}=\pi_{0}+e_{k}\left(\pi_{1}+\lambda\right) P_{j}+\xi_{j}^{\prime}
$$

The strategy implemented in this paper amounts to estimating equation (6) using weighted least squares for various cohorts. The structure of the program implies that coefficients in equation (6) should be 0 for $k>13$. This restriction will provide a test of the identification assumption in this paper, which is that there were no other region-specific changes in the returns and costs of education correlated with the program.

If each region is an isolated labor market, returns to education in a given region do not depend on the average education in other regions $\left(\beta_{2}=0\right)$, and the coefficient of $P_{j}$ in equation (6) is the reduced-form effect of the program on average education (taking into account potential changes in quality induced by the program). If, on the contrary, returns to education do not depend on the average education in the region but only on the average education in the country as a whole $\left(\beta_{1}=0\right)$, then it identifies by how much the supply of educated labor shifted as a response to the program (a behavioral parameter of interest). In the most general model, I am able to identify only a mixture of the two.

I can now use equation (1) to express the average of the logarithm of the 1995 earnings for a given region and cohort as follows:

$$
y_{j k}=a_{j k}+\frac{1}{N_{j k}} \sum_{i=1}^{N_{j k}} b_{i j k} S_{i j k}=a_{j k}+b_{j k} S_{j k}+\epsilon_{j k},
$$

where $N_{j k}$ is the number of individuals in region $j$, in cohort $k$, and $\epsilon_{j k}=\frac{1}{N_{j k}} \sum_{i=1}^{N_{j k}} \nu_{i} \frac{\nu_{i}-\omega_{i}}{\phi}$. 
Using the definition of $b_{j k}$ (equation (4)) and replacing $S_{j k}$ (equation (6)), I get the following expression of the difference between the logarithms of the 1995 wages of an old cohort and a younger cohort:

$$
y_{j k}-y_{j 0}=a_{j k}-a_{j 0}+e_{k}\left(\bar{b} \pi_{1}+\lambda \beta_{3}\right) P_{j}+\eta_{j},
$$

where $\bar{b}$ is the average return to education of the cohort educated in the old schools (i.e., before any change in quality due to the program). The term $\eta_{j}$ represents the deviation of regionspecific returns to education from the national average. It could be related to program intensity for two reasons. First, there is a relationship between the education in the old cohort (which determines, to a large extent, the program placement) and the regional returns to education (this is an equilibrium relationship as in equations (2) and (4), therefore, the sign of the correlation is uncertain). Second, general equilibrium effects may cause returns to education to decrease more (and therefore be lower in 1995) in the regions that received more schools.

As in the case of education, the identification strategy is to estimate equation (8) for various cohorts. I test whether the coefficients of the program are equal to 0 for $k>13$. This is a test of the identification assumptions that regional changes in the intercept of the earning function are uncorrelated with the program and that region-specific returns do not differ in a way that is related to the program intensity. 19

Estimating equation (8) gives us the average impact of the program on private wages due to the average increase in education and potential changes in school quality. Wages are observed in 1995, after returns have reached their new equilibrium level. Therefore, this does not account for the potential loss due to the reduction in returns to schooling coming from general equilibrium effects. If I assume, in addition, that $\lambda$ is equal to 0 , namely that the program did not affect the quality of education, the coefficient of $P_{j}$ in equation (8) reduces to $e_{k} \bar{b} \pi_{1}$. An estimate of $\bar{b}$, the average returns to education, can then be obtained by dividing the coefficients of $P_{j}$ in the education equation and in the wage equation. This is a simple instrumental variables estimator (indirect least squares). Two-stage least squares estimators will be presented in section V. In addition, if there is a subgroup where $\pi_{1}$ is known to be equal to 0 , the coefficient of $P_{j}$ in equation (8) in this subgroup gives the pure quality effect of the program on earnings. This fact will be used to test the assumption that $\lambda$ is indeed 0 .

To conclude, note that the above argument is valid under the assumptions of linear individual 
heterogeneity and returns to education. Under these assumptions, changes in education caused by the program are not correlated with individual-specific returns. If $\phi$ (the second derivative of the cost of schooling function) differed across individuals, or if returns to education were not linear, individual responses to the program might depend on returns to education. An instrumental variable estimator does not provide a consistent estimator of average returns to education in this case (see Heckman and Robb (1985) and Card (1995, 1999)). As shown by Angrist and Guido Imbens $(1994,1995)$ in the case of a binary instrument, if the instrument satisfies the two assumptions of independence and monotonicity, the instrumental variable estimate is a weighted average of returns to education for the individuals who, as a result of the program, changed their level of education. It is a causal parameter of interest for policy evaluation, since it measures the returns for people affected by this policy.

\section{Effect on Education}

\section{A. Basic Results}

I start by estimating equation (6) for two large cohorts. In practice, I estimate

$$
S_{i j k}=c_{1}+\alpha_{1 j}+\beta_{1 k}+\left(P_{j} * T_{i}\right) \gamma_{1}+\left(\mathbf{C}_{\mathbf{j}} * T_{i}\right) \delta_{\mathbf{1}}+\epsilon_{i j k},
$$

where $T_{i}$ is a "treatment dummy" indicating whether the individual belongs to the "young" (or treated) cohort in the subsample, $c_{1}$ is a constant, $\beta_{k}$ is a cohort of birth fixed effect, $\alpha_{j}$ is a district of birth fixed effect, $P_{j}$ denotes the intensity of the program in the region of birth, and $\mathbf{C}_{\mathbf{j}}$ is a vector of region specific variables. ${ }^{20}$

In table 4 (columns $1-3$ ), I present estimates of equation (9) for two subsamples. In panel A, I compare children aged 2 to 6 in 1974 with children aged 12 to 17 in 1974. In column 1, I control only for the interaction of a cohort of birth dummy and the population aged 5 to 14 in 1971. ${ }^{21}$ The suggested effect is that one school built per 1,000 children increased the education of the children aged 2 to 6 in 1974 by 0.12 years for the whole sample, and 0.20 years for the sample of wage earners.

This result relies on the identification assumption that there is no omitted time-varying and region specific effects correlated with the program. The allocation of schools to each region was a function of the enrollment rate in the region in 1972. Therefore, this assumption will be violated 
if changes in expected and actual determinants of returns and costs of education are correlated with initial levels. ${ }^{22}$ Moreover, it will be violated if the allocation of other governmental programs initiated as a result of the oil boom (and potentially affecting education) was correlated with the allocation of INPRES schools. The identification assumption might, therefore, be satisfied only after controlling for these factors. Thus, I present specifications that control for the interactions between cohort dummies and the enrollment rate in the population in $1971,{ }^{23}$ as well as for interactions between cohort dummies and the allocation of the water and sanitation program, the second largest INPRES program centrally administered at the time. Controlling for enrollment rate and the water and sanitation program makes the estimates higher (columns 2 and 3), suggesting that the estimates are not biased upward by mean reversion or omitted programs.

In table 4, panel $\mathrm{B}$, I show the results of the control experiment (comparing the cohort aged 12 to 17 to the cohort aged 18 to 24 in 1974). The impact of the "program" is very small and never significant. The coefficients are statistically different from the corresponding coefficients in panel A.

Figure 1 plots the difference in education between the young and the old cohorts against the program intensity in each region. The regression line corresponds to the weighted least squares estimate of equation (6) (the coefficients are presented in table 4, column 1). I also plotted the kernel estimator, which shows that the effect of the program on education is approximately linear. This justifies the assumption of linearity used to derive equation (6). In the control experiment (panel B), the regression line as well as the nonparametric regression are flat.

\section{B. Reduced-Form Evidence}

The identification strategy discussed in the previous section can be generalized to an interaction terms analysis.

Consider the following relationship between the education $\left(S_{i j k}\right)$ of an individual $i$, born in region $j$, in year $k$, and his exposure to the program:

$$
S_{i j k}=c_{1}+\alpha_{1 j}+\beta_{1 k}+\sum_{l=2}^{23}\left(P_{j} * d_{i l}\right) \gamma_{1 l}+\sum_{l=2}^{23}\left(\mathbf{C}_{\mathbf{j}} * d_{i l}\right) \delta_{\mathbf{1 l}}+\epsilon_{i j k},
$$

where $d_{i l}$ is a dummy that indicates whether individual $i$ is of age $l$ in 1974 (a year-of-birth dummy). In these unrestricted estimates, I measure the time dimension of exposure to the 
program with 22 age dummies (for being 2 to 23 in 1974). The omitted dummy is the dummy for being 24 in 1974 (individuals aged 24 in 1974 form the control group). Each coefficient $\gamma_{1 l}$ can be interpreted as an estimate of the impact of the program on a given cohort. This is simply a generalization of equation (6) to estimate cohort-by-cohort contrasts. Because children aged 13 and older in 1974 did not benefit from the program, the coefficients $\gamma_{1 l}$ should be 0 for $l>12$ and start increasing for $l<$ some threshold (the oldest age at which an individual could have been exposed to the program and still benefited from it). The only a priori restriction about this threshold is that it is smaller than 12 .

Table A1 presents unrestricted reduced-form estimates of three specifications. These reducedform estimates allow me to check whether the $\gamma_{1 l}$ in equation (10) follows the expected pattern. In figure 2, I have plotted the $\gamma_{1 l}{ }^{24}$ Each dot on the solid line is the coefficient of the interaction between a dummy for being a given age in 1974 and the number of schools constructed per 1,000 children in the region of birth (a 95 percent confidence interval is plotted in broken lines). Each dot summarizes the effect of the between-regions variation in program intensity on a given cohort. For example, a child aged 6 in 1974 received 0.2 additional years of education if he was born in a region that received one more INPRES schools per 1,000 children. These coefficients fluctuate around 0 until age 12 and start increasing after age 12. As expected, the program had no effect on the education of cohorts not exposed to it, and it had a positive effect on the education of younger cohorts. All coefficients are significantly different from 0 after age 8 . To show more clearly the discontinuity in the trend, I plotted in figure 3b a smoother version of the same data: for each $l$, I plotted the average of $\gamma_{1 l}, \gamma_{l-1}$, and $\gamma_{l+1}$. The coefficients are close to 0 until age 11, and then they increase sharply. This pattern is similar across specifications. Omitted changes in regional conditions should have affected the education of some children older than 12 in 1974 (for example, an increase in regional income would have affected junior high school education at least as much as primary education) and, therefore, would not generate the same pattern. From these graphs, it therefore appears that the identification strategy is reasonable and that the program had an effect on education. 


\section{Restricted Estimation}

Instead of testing whether the $\gamma_{1 l}$ are equal to 0 for $l \geq 13$, one can impose this restriction. The equation to be estimated is then

$$
S_{i j k}=c_{1}+\alpha_{1 j}+\beta_{1 k}+\sum_{l=2}^{12}\left(P_{j} * d_{i l}\right) \gamma_{1 l}+\sum_{l=2}^{12}\left(\mathbf{C}_{\mathbf{j}} * d_{i l}\right) \delta_{\mathbf{1 l}}+\epsilon_{i j k} .
$$

The omitted group (the control group) is now formed of individuals aged 13 to 24 in 1974 . This is a more efficient way to estimate the program effect and leads to more precise estimates.

Columns 1-3 in table 5 show the coefficients of the interactions between age in 1974 and the intensity of the program in the region of birth in three specifications in the whole sample (columns 4-6 show the same results for the sample of wage earners). In all columns, the estimated effect is positive after age 10. All coefficients are significantly greater than 0 after age 8 . All sets of interactions are statistically different from 0 (the F-statistic for the null hypothesis is presented at the bottom of the table). The coefficients generally increase with date of birth (decreasing with age), except for a high value at age 9 and a decline between ages 6 and 5 . They increase faster between ages 12 and 9 than they do subsequently; this fact suggests that once the education level in the population reaches a certain point, increasing it by building primary schools becomes more difficult.

The estimates in column 1 (without controls) suggest that one school per 1,000 children increases the education of the youngest children by 0.14 years. On average, 1.98 schools were built per 1,000 children. This implies that at its mean value, the program caused an increase in education of 0.27 years for these children (the average education in the sample is 7.98 years). As before, controlling for enrollment rate in 1971 (column 2) and the water and sanitation program (column 3) make the estimate slightly higher. In columns 4-6, I present the same estimates for the subsample of wage earners. The program effect is higher for wage earners than it is in the whole sample.

More insight into why and how this program was effective is obtained by examining its impact in different types of regions. In table 6 (panel A), I present results equivalent to the specification in table 4 (equation (9)) for various subsamples of regions of birth. In columns 2 and 3, I present the program effect in sparsely and densely populated regions. In sparsely populated regions, each school constructed is likely to reduce the distance to school significantly 
(if the schools are placed relatively evenly in space). In densely populated regions, the main effect will not be to reduce the distance to school, but to increase the availability of slots or reduce the overcrowding of old schools. Therefore, the difference between the program effects in these two types of regions will provide some information on whether reducing distance to school or overcrowding of schools was the reason why the program was effective. The estimated program effect is 0 in densely populated regions, while it is 0.19 in sparsely populated regions (columns 2 and 3). This suggests that reducing the distance to school was the most important effect of the program. This interpretation should, however, be taken with caution, since this difference may come from other characteristics correlated with density. In columns 4 and 5, I present the results in provinces where the incidence of poverty in 1976 was higher and lower than the Indonesian average. I find a larger effect in poor provinces. In columns 6 and 7, I divide the sample into regions where the education of the cohort not exposed to the program (men born between 1950 and 1962) was lower or higher than the median (3.08 years of education). Results are similar for both sets of regions.

In summary, it appears that the school construction program had an impact on education. The causal interpretation of these estimates is supported by preprogram tests. It should be recalled that this program was accompanied by a general effort by the Indonesian government in favor of education, a priority of the second five-year plan. As part of this effort, primary school fees were suppressed in 1978 ((World Bank 1990a, World Bank 1990b)). Therefore, these results cannot be generalized to less favorable contexts without applying caution.

\section{At What Level of Education Was the Program Effective}

The impact of the program on welfare depends on whether it primarily affected children with a low or a high level of education. For this reason, it is important to examine at what level of education the program was effective. The simplest way to investigate this question is to use a difference in differences estimator. ${ }^{25}$

I group the regions into high and low program regions and consider a cohort aged 2 to 6 in 1974 and a cohort aged 12 to 17 in 1974. Instead of considering only differences in group means, I consider differences in the cumulative distribution functions (CDF) of education (the probabilities of completing any given level of education or less). Figures 4 and 5 show that in 
both regions, the CDF of education in the younger cohort stochastically dominates the CDF of education in the older cohort. Moreover, the CDF of education in the low-program regions stochastically dominates the $\mathrm{CDF}$ of education in the high-program regions for both cohorts, a consequence of the higher intensity of the program in regions with lower initial enrollment. Figure 6 plots the differences in $\mathrm{CDF}$ between the two cohorts for both type of regions. The between-cohort differences in CDF is larger in the low-program region for the first five years of education, but lower after the sixth year (the last year of primary school). Figure 7 shows the difference in differences in CDF (the 95 percent confidence interval is plotted in broken lines). The dot for the fifth year of education, for example, indicates that the program induced six percent of the sample to complete six years of education or more (i.e., graduate from primary school) instead of five or less. This shows a positive effect of the program at all primary school levels. It had no effect at the junior high school level. A significantly negative effect of the interaction is shown for levels of education of nine years and above.

I obtain more precise estimates by including a full set of region-of-birth and year-of-birth dummies. To estimate an equivalent of this difference in differences controlling for these variables, I estimate a linear probability model for the probability of completing $m$ years of education or less. For $S_{i j k m}$, a dummy that indicates whether the individual $i$, born in region $j$, in year $k$, completed $m$ years of education or less, and for $P_{j}$, a dummy indicating whether the child was born in a high program region, I estimate the following equation:

$$
S_{i j k m}=c+\alpha_{j}+\beta_{k}+\left(P_{j} * T_{i}\right) \kappa_{m}+\epsilon_{i j k}
$$

The $\kappa_{m}$, for $m=0$ to 19 , are the values of the estimated impact of the program at each level of education. They are plotted in figure 8 (the 95 percent confidence interval is plotted in broken lines).

The shape of this function and the shape of the function estimated from the difference in differences in the CDF are similar. Both are rising until the fifth year of education, decreasing until the twelfth, and slightly increasing thereafter. A maximum of about 6 percent of the sample living in high program regions were induced to complete at least primary school. This also shows some impact of the program on the probability of completing lower secondary school (1.5 percent of the sample is estimated to have been induced by the program to complete 7 th, 
8th, and 9th grade or more). ${ }^{26}$ There is a negative difference in differences at the senior high school level.

The analysis of the CDF suggests that the program increased schooling, but almost entirely through increasing primary schooling. This provides additional evidence that the assumption underlying the identification strategy is reasonable. The estimated effect of the program for the levels of education that it did not target is small or nil. ${ }^{27}$

The program could have induced more marginal people to complete primary school and move on to junior high school. ${ }^{28}$ However, the direct and indirect costs of junior high school are much higher than the costs of primary education and were not equalized across regions at the time. Individuals induced by the program to complete primary school are presumably those who were facing a high cost of education before the program. Therefore, the marginal cost of a year in junior high school must have remained high, since this was not affected by governmental intervention. This explains why we do not observe large spillovers. The test of human capital versus sorting models of returns to education proposed by Kevin Lang and David Kropp (1986) provides another interesting aspect of this result. They show that the sorting model implies that compulsory attendance laws, which affect the education of the low-skill workers, should also affect the education of the high-skill workers (who have to get more education to show that they are different). Under the human capital model, compulsory attendance laws should not affect the education of people who are not directly constrained by them. The INPRES program directly affected primary education only, but under the sorting model, it could have led some people who would have completed only primary school to complete more years of education. The results in this paper suggest that the human capital model of education might describe Indonesia better than the sorting model.

The program was effective in increasing education, in particular at the primary school level. Did it increase human capital? One way to answer that question is to look at the effect of the program on wages. 


\section{Effect on Wages}

\section{A. Basic Results}

I start by estimating a specification equivalent to equation (8) for the experiment of interest and the control experiment. As for education (equation (9)), I estimate:

$$
y_{i j k}=c_{1}+\alpha_{1 j}+\beta_{1 k}+\left(P_{j} * T_{i}\right) \gamma_{1}+\left(\mathbf{C}_{\mathbf{j}} * T_{i}\right) \delta_{\mathbf{1}}+\epsilon_{i j k},
$$

where $y_{i j k}$ is the logarithm of the 1995 wage of an individual $i$, born in region $j$, in cohort $k$.

Results are presented in table 4 (columns 4-6) and in figure 1 . In table 4 , panel A, I set $T_{i}$ equal to 1 for children aged 2 to 6 in 1974, and I use children aged 12 to 17 as the comparison group. In figure 1, panel A, I plotted the increase in wages between the same two cohorts against the program intensity, as well as the weighted least squares regression line (the coefficients of which are given in column 4 in table 4) and the kernel regression curve. In table 4, panel B, I set $T_{i}$ equal to 1 for children aged 12 to 17 in 1967 and used children aged 18 to 24 as the comparison group. Corresponding evidence is plotted in figure 1, panel B.

In table 4 , panel $\mathrm{A}$, the estimates range from 1.5 percent to 2.7 percent. As in the case of education, the estimates increase when I control for enrollment rates in 1971 and for the

allocation of the water and sanitation program, although none of these estimates are significantly different from each other. In panel B, in all specifications, the interaction coefficient is small and not significantly different from 0 . However, these estimates are imprecise and I cannot reject equality of the coefficients in panels A and B (although the point estimates are much smaller in panel B). Qualitatively, the results of estimating this reduced-form expression nevertheless lead to similar conclusions as for education. The program seems to have affected average wages, the estimates are not smaller when control variables are introduced, and the point estimates of the program effect in an untreated sample is smaller and close to 0 .

\section{B. Reduced-Form Evidence}

As for education, I can now write an unrestricted reduced-form relationship between exposure to the program and the logarithm of the wage of an individual $\left(y_{i j k}\right)$ 


$$
y_{i j k}=c_{2}+\alpha_{2 j}+\beta_{2 k}+\sum_{l=2}^{23}\left(P_{j} * d_{i l}\right) \gamma_{2 l}+\sum_{l=2}^{23}\left(\mathbf{C}_{\mathbf{j}} * d_{i l}\right) \delta_{\mathbf{2}}+v_{i j k},
$$

where $\alpha_{2 j}$ is a region-of-birth effect and $\beta_{2 k}$ is a cohort-of-birth effect. $P_{j}, \mathbf{C}_{\mathbf{j}}$ and $d_{i l}$ are defined as in the education equation: $P_{j}$ is the intensity of the program in the region of birth, $\mathbf{C}_{\mathbf{j}}$ is the vector of control variables, and $d_{i l}$ is a dummy indicating whether individual $i$ was of age $l$ in 1974.

The $\gamma_{2 l}$ should be 0 for $l$ greater than 12 and start increasing after some threshold. Moreover, if the program affected wages only through its effect on education, the coefficients $\gamma_{2 l}$ should track the $\gamma_{1 l}$ (in the education equation). In particular, the threshold after which the coefficients $\gamma_{2 l}$ start to increase should be the same as the threshold after which the coefficients $\gamma_{1 l}$ start to increase. The $\gamma_{2 l}$ should also track the up and downs of the $\gamma_{1 l}$.

Table A1 presents the results for the three specifications for which I had estimated the education equation. Again, graphs help interpret the reduced form coefficients. In figure 3a, the $\gamma_{2 l}$ are plotted in a dotted line. They are oscillating until age 10 and start increasing after age 11. The coefficients of the interactions for education and wages track each other. Figure 3b presents the same data, but shows more clearly the impact of the program. The values on this graph are smoothed and the scales are adjusted. In this figure, the change in trend after age 11 is very apparent. The program began having a positive effect on wages and education at that point.

\section{Restricted Estimates}

In columns 7-9 in table 5, I present estimates of the equation

$$
y_{i j k}=c_{2}+\alpha_{2 j}+\beta_{2 k}+\sum_{l=2}^{12}\left(P_{j} * d_{i l}\right) \gamma_{2 l}+\sum_{l=2}^{12}\left(\mathbf{C}_{\mathbf{j}} * d_{i l}\right) \delta_{\mathbf{2 1}}+v_{i j k} .
$$

It is more difficult to precisely estimate the effect of the program on wages than on education, because wages fluctuate more and the sample is smaller (since wages are not collected for self-employed people). Not surprisingly then, I find that few coefficients are individually significant and that the F-statistics for the significance of the joint set of instruments are small. Qualitatively, the results parallel the estimated effects on education. No effect is found for children aged 10 or older in 1974. The coefficients are positive for younger children (except at age 
7). The coefficients of the interactions are generally decreasing with age. The estimates are higher when I control for enrollment rate and for the water and sanitation program. The last line in this table indicates that constructing one school per 1,000 children increased the 1995 wages of individuals aged 2 in 1974 by 1.6 percent to 4.0 percent. The average number of schools constructed per 1,000 children is 1.89 in the sample with valid wage data. Thus, on average, the program caused a $3-7$ percent increase in the wages of this cohort.

In table 6 (panel B), I present the estimates of equation (13) for different subsamples. The variations of the program effect across subsamples parallel the variations of the program effect on education. In particular, I see no effect on wages in regions where there is no effect on years of education. This suggests that the program effect on wages was probably caused by the changes in years of education. In the next section, I use this to construct instrumental variables estimates of the effect of education on wages.

\section{Estimating Returns to Education}

The identification assumption that the evolution of wages and education across cohorts would not have varied systematically from one region to another, in the absence of the program, is sufficient to estimate the impact of the program. Since the intervention was to build primary schools, the program effect on wages was most probably caused by changes in education. The additional assumption needed is that the program had no effect on wages other than by increasing education. I can, therefore, use this program to construct instrumental variables estimates of the impact of additional years of education on wages. The most serious concern, for this interpretation, is that the program might have affected both the quality and the quantity of education and that changes in wages could reflect both effects. Below, I examine whether there is evidence that this is a serious problem.

\section{A. Indirect Least Squares Estimates}

Following the discussion in section III, I calculate indirect least squares estimates of returns to education by dividing the estimate of the program effect on wages by the program effect on education. For example, dividing the estimate of table 4, panel A, column 4, by the corresponding estimate in column 1 for wage earners, I obtain an estimate of average returns to education of 
7.5 percent. Adding controls, I find 8.6 percent and 10.4 percent. This strategy can be extended to use all the information available, by using a two-stage least squares (2SLS) strategy instead of the indirect least squares (ILS) approach.

\section{B. Two-stage Least Squares Estimates of the Returns to Education}

Estimates of equation (11) are of intrinsic interest because they provide an assessment of the impact of the program on education. But they also represent the first stage of a two-stage least squares estimation of the impact of education on wages. Equation (1) characterizes the causal effect of education on wages:

$$
y_{i j k}=a_{i j k}+b_{i j k} S_{i j k}
$$

Rewrite this expression as

$$
y_{i j k}=d+\alpha_{j}+\beta_{k}+S_{i j k} \bar{b}+\eta_{i j k}
$$

where $\alpha_{j}$ and $\beta_{k}$ denote region-of-birth and cohort-of-birth effects. The region-specific error terms, the cohort-specific error terms, and the individual error terms incorporate individual and regional differences in returns to education and in the specific intercepts.

Under the assumptions discussed in section III, the interactions between the age in 1974 and the program intensity in the region of birth are available as instruments for equation (16). By limiting the set of instruments to the interactions in equation (11) (the age dummies for $l \leq 12$ ), I avoid potential small sample bias caused by the use of many weakly correlated instruments. Moreover, the instruments have been shown to have a good explanatory power in the first stage, which indicates that the 2SLS estimates should not be affected by this problem. ${ }^{29} \mathrm{I}$ also estimated the same equation using a single instrument, the interaction of being in the "young" cohort and the program intensity in the region of birth. Equation (16) can also be modified to incorporate control variables as follows:

$$
y_{i j k}=d+a_{j}+b_{k}+S_{i j k} \bar{b}+\sum_{l=2}^{12}\left(\mathbf{C}_{\mathbf{j}} * d_{i l}\right) \pi_{\mathbf{l}}+\eta_{i j k} .
$$

The results are presented in table 7, panel A1 (panel A2 presents results with the logarithm of monthly earnings as the dependent variable). The first line shows the OLS estimate. The 
estimated returns to education is 7.8 percent and is not affected by introducing control variables. This is lower than OLS estimates in Indonesia in older samples, but consistent with estimates in other Indonesian data sets of the 1990's and with the decline in estimated returns to education over time. The World Bank (1990b) reports that estimates decreased from 19 percent in 1982 to 10 percent in 1986 .

The second line presents 2SLS estimates of equation (17) (shown in square brackets are the F-statistics of the overindentifying restrictions test). In columns 1-3, I present the 2SLS estimates for the three specifications used throughout the paper. In column 1, the number of children in 1971 is the only control variable. The point estimate (6.75 percent) is slightly lower than the OLS estimate, although I cannot reject equality. In column 2, I introduce interactions between the enrollment rate in 1971 and year-of-birth dummies. The point estimate is higher than without the controls (8.1 percent). When I introduce a control for the water and sanitation program, the estimate is again slightly higher (10.6 percent). In the third line, I present the 2SLS estimate using only one instrument. The results are very similar to the IV estimates using more instruments (but slightly less precise, since they use less variation).

These 2SLS estimates are not very different from the OLS estimate. The general belief in the development literature (Behrman (1990), Strauss and Thomas (1995)) is that OLS estimates are likely to be biased upward due to omitted family and community background variables, but this does not seem confirmed here. ${ }^{30}$

On the other hand, most studies in industrialized countries find instrumental variables (IV) estimates that are higher than OLS estimates, which is not what I find here (see Card (1995,1999), Orley Ashenfelter, Colm P. Harmon and Hessel Oosterbeek (1998)). Card (1999) discusses several possible explanations why IV estimates tend to be higher than OLS estimates. I consider them briefly to determine whether they apply in this context. The first explanation, following Zvi Griliches (1977), is that ability bias in the OLS estimates of returns to schooling is relatively small and that OLS estimates may in fact be biased downward due to measurement errors. My results are consistent with the idea that the ability bias and the measurement error bias more or less cancel each other out in the Indonesian context. A second explanation is that the IV estimates are biased even further upward than the OLS estimates, due to unobserved differences in earning ability between the "treatment" and "control" groups. These differences 
in earnings are then "blown up" when they are divided by small differences in schooling. Card notes that this problem is likely to be less important when the instruments exploit large variations in education and an interaction between two sources of variations, which is the case of my IV estimates. A third explanation, proposed by Ashenfelter, Harmon and Oosterbeek (1998) is that researchers prefer to report estimates with high t-statistics. With a relatively large sample and important variations in schooling, the standard errors of the IV estimates are small enough that even estimates smaller than OLS still have t-statistics above 2.

Finally, Card (1995) shows that the 2SLS estimate might not be an estimate of average returns to schooling. People affected by the instruments might be people who have higher marginal returns to schooling. This is the case, in particular, if returns to education are concave and individuals with low levels of schooling are more affected than others. Only people who would have completed less than primary school were affected by the program, as described in section IV. However, there is no evidence that returns to education are concave in Indonesia. Estimating nonparametrically the shape of the true causal response function would be difficult, since the source of exogenous variation I use in this study affects only primary education. But some indication that the returns are not concave is given by OLS estimation using a dummy for each year of education. These coefficients are plotted in figure 9. Estimated marginal returns vary little until nine years of education but are high for the twelfth year of education (the last year of senior high school) and the thirteenth year of education. The high returns for years corresponding to diplomas indicate a "sheepskin effect," found in the United States as well (Thomas Hungerford and Gary Solon (1987), David A. Jaeger and Marianne E. Page (1996)). Strauss and Thomas (1997) also found evidence of apparent convex returns to education in urban Brazil. $^{31}$ If returns are, in reality, linear or even convex in developing countries, the phenomenon of "discount rate bias" (Kevin Lang (1993)) emphasized by Card should not be present, which would again explain why OLS and 2SLS estimates are similar in my study.

In table 6 , panel $\mathrm{C}$, I examine whether returns to education vary across regions. ${ }^{32}$ They are higher (11 percent) in sparsely populated regions and in regions where the average education level of cohorts not exposed to the program is low (12 percent). They seem to be lower in regions where initial education was high, although the standard error of this estimate is too large to be conclusive. This last result is consistent with the idea that the general equilibrium effect of 
an increase in education is to depress the returns, but it suggests that even after the program, returns were still higher in regions that received more schools.

I now turn to two potential sources of bias: the assumption that the program had no impact on wages other than through the increase in the quantity of education, and problems arising from sample selection.

\section{Could Change in Quality Bias the 2SLS Estimates?}

As I discussed in section III, estimates of returns to education are biased if the program affects both the quality and the quantity of education. I examine two pieces evidence that suggest that the program did not substantially affect the quality of education.

First, I calculated average pupil/teacher ratios in 1973/74 and 1978/79. In both high- and low- program regions, the average pupil/teacher ratio increased slightly from 29.7 to 31.5 in highprogram regions, and from 28.4 to 30.1 in low-program regions. The difference in differences is very close to 0 . No systematic difference in quality, as measured by this indicator, is apparent. I also ran a regression of the change in pupil/teacher ratios on the number of schools per children built in the program. The coefficient is negative, very small, and not significantly different from 0. However, quality of education could still have deteriorated if the newly hired teachers had been less qualified.

Second, I use the fact that the program did not increase the education of people completing nine years of education or more (as shown in section IV). The educational attainment of these people was not affected by the program. Therefore, their wages should not be affected either. In figure 10, I show the coefficients of the interactions between the program intensity and age dummies in the wage and education equations, in the sample of people whose level of education is greater than $9 .{ }^{33}$ In contrast to figures $1-3$, no specific pattern emerges in either equation: the interaction coefficients are fluctuating (they become negative for the youngest individuals in the education equation) and there is no rupture in trend after age 12. The evidence in table 6 can be interpreted along the same lines. In densely populated regions (column 4), the program has no effect on years of education. If the quality of education had changed and this had affected wages, then I should see an effect of the program on wages even in this region. ${ }^{34}$

These two separate pieces of evidence lend some support to the assumption that the increase 
in wages was due mainly to the increase in the quantity of education. There is no clear evidence against the assumption that the program affected only the quantity of education.

\section{Correction for Sample Selection}

The returns to education are estimated in a selected sample: only 45 percent of the individuals in the sample are working for a wage. Most remaining individuals are self-employed.

The probability of working for a wage is potentially affected by education. To examine this, I use 2SLS to estimate

$$
w_{i j k}=d+a_{j}+b_{k}+e_{i j k} \lambda+\sum_{l=2}^{12}\left(\mathbf{C}_{\mathbf{j}} * d_{i l}\right) \pi_{\mathbf{l}}+\eta_{i j k},
$$

where $w_{i j k}$ is a dummy variable indicating whether an individual reports a positive wage. Estimates of this equation are presented in table 7 , panel B1. The OLS estimate is much smaller than the IV estimate (the estimate of the impact of an additional year of education on the probability of working for a wage changes from 3.3 percent to 10.1 percent). The probability of working for a wage is affected by education.

This is an interesting result in itself. However, this casts some doubts on the validity of the 2SLS estimate of returns to education. Because the probability of working for a wage is also affected by schooling, the sample selection is likely to induce a correlation between the instruments and the error in equation (17) (the conditional expectation of the error given the instruments and the fact that an individuals reports a positive wage may not be 0 ). The ideal solution to this selection problem would be to find an instrument that is randomly assigned in the population with positive wages. Failing that, several econometric solutions have been proposed. Most rest on exclusion assumptions that would be strong in this context.

I implement two alternative procedures to investigate whether sample selection is likely to be an important problem in this case. First, I implement a sample correction procedure. Second, I use another Indonesian survey to impute an income to self-employed individuals in my sample. Results are not very sensitive to either modification.

First, I follow a suggestion introduced by Heckman and Hotz (1989), then elaborated by Hyungtaik Ahn and James L. Powell (1993) and Angrist (1995a), to condition in the second 
stage on the probability of selection given the instruments. In practice, I estimate the equation

$$
w_{i j k}=c_{3}+\alpha_{3 j}+\beta_{3 k}+\sum_{l=2}^{12}\left(P_{j} * d_{i l}\right) \gamma_{3 l}+\sum_{l=2}^{12}\left(\mathbf{C}_{\mathbf{j}} * d_{i l}\right) \delta_{\mathbf{3} \mathbf{1}}+\epsilon_{i j k},
$$

and use the predicted value for $w_{i j k}$ (the probability of being selected given the instruments) and the square of the predicted value as additional regressors in equation (17):

$$
y_{i j k}=d+a_{j}+b_{k}+S_{i j k} \bar{b}+\sum_{l=2}^{12}\left(\mathbf{C}_{\mathbf{j}} * d_{i l}\right) \pi_{\mathbf{l}}+{\widehat{w_{i j k}}} \mu_{1}+{\widehat{w_{i j k}}}^{2} \mu_{2}+\eta_{i j k},
$$

where $\widehat{w_{i k j}}$ is the predicted value from equation (19). The instruments are interactions between year-of-birth dummies (for people 12 or younger in 1974) and program intensity in the region of birth.

The result of the introduction of the correction for sample selection is presented in table 7 , column 5 (panel A1). The change in the coefficient is small. It changes from 8.1 percent (in column 3) to 9.2 percent. To check the sensitivity of this result to functional form assumptions, I have run similar specifications controlling for higher-order terms of the selection probability (cubic and fourth power), and the estimates do not change much.

I applied the same sample correction procedure to the other specifications. Conventional estimates and the selection-corrected estimates are similar. This suggests that selection bias does not have a big impact on the estimation of the coefficient of education.

A problem with this procedure is that I use functions of the year and region-of-birth interactions both as instruments and as controls. The second stage is still overidentified (there are now 12 instruments for 3 parameters to estimate). But the identification is fragile. It rests on the fact that I use several instruments to measure the program intensity. This leads, in particular, to a lower F-statistic in the first stage, and to larger standard errors in the second stage. An alternative approach is to impute an income for self-employed individuals and examine whether the results change when the estimation is performed in this "completed sample."

To this end, I use the income and expenditure module of the 1993 SUSENAS survey. Over 50,000 individuals are included in this module. The SUSENAS does not report the place of birth of the individuals. Households report the members' occupations and the sector of activity from which they derive their main source of income. In addition, the survey collects information on wages received by each member of the household, income derived from the sale of products and 
services of the household business (or farm), and operating expenses related to it. I define the income accruing to the household from each household business as the difference between sales and expenses for this business. I calculate the average income derived from the main activity of the household for cells defined by sector (9 industrial sectors and services and 4 types of agricultural activities), status, and urban/rural residence. To check the consistency between the two sources, I report in table 1 the average monthly income of wage earners and their average income imputed using this procedure. The two figures are quite close. The difference is explained by the fact that the SUSENAS was done in 1993 while the SUPAS was in 1995. The average monthly income for self-employed individuals is smaller than for wage earners.

The goal of this exercise is to examine whether the results are sensitive to the inclusion of self-employed individuals in the estimation. Therefore, I "complete" the sample by defining the dependent variable as the logarithm of monthly earnings if they are recorded in the SUPAS data (for individuals working for pay) and the logarithm of the average income from the SUSENAS in the individual's occupation cell all for self-employed individuals (multiplied by the wage inflation factor defined as the ratio of the average wage from the SUPAS and the average income of wage earners imputed from the SUSENAS ). ${ }^{35}$

The results are presented in table 7, panel B2. They must be compared to the results in panel A2, where the dependent variable is the logarithm of monthly earnings of wage earners. In all cases, the estimates using the completed sample are smaller than those using the sample of wage earners. They are quite close, except in the specification controlling for the water and sanitation program (column 3), where it drops to 3.5 percent. This particular result is surprising, but the fact that the returns for the complete sample are somewhat smaller than for the sample of wage earners indicates that returns to education might be higher in the wage sector than among the self-employed.

This additional evidence supports the idea that sample selection is not an important problem in this application. A statistical sample selection correction procedure does not change the estimates significantly. Using the complete sample by imputing an income to self-employed individuals also produces similar estimates in most specifications. 


\section{Comparing Costs and Benefits}

The estimates of the program's effect on wages can be used to compare the costs of building and operating the new schools to the additional wealth they generated, under the assumption that the increase in wages represents an increase in human capital and that the general equilibrium effects were not important. ${ }^{36}$ Note that in this case, the increase in wages underestimates the total benefit generated by the program: the increase in education is likely to affect other outcomes (fertility, child morbidity and mortality, etc.). ${ }^{37}$ These calculations require additional assumptions and should be taken with considerable caution. Nevertheless, it is useful to evaluate the magnitude of the consequences of such a large-scale program: the discounted sum of the cost of construction alone from 1973 to 1979 represented more than 2 percent of Indonesia's GDP in 1973.

The presidential instructions indicated each year the costs of building the new schools in each region and the number of teachers to be allocated in each school. The total cost of building over 61,000 schools reached slightly over 5 billion 1990 U.S. dollars. Detailed information on the cost of education in Indonesia has been collected by Daroesman (1971). She used a survey of schools that she had conducted and various administrative sources. I used her data on teachers' salaries, recurrent expenditures, and the costs of teacher training in 1971. Using my data, I then estimated the average wage of a primary school teacher in 1995, and I interpolated linearly the wage between 1971 and 1995 (this represents an annual growth slightly higher than the growth of Indonesia's GDP over the period). School buildings constructed at the time were meant to remain active for twenty years (Daroesman (1971)). ${ }^{38} \mathrm{I}$ am, therefore, assuming that the program lasted for twenty years. These and other assumptions are summarized in table 8, panel B.

In summary, yearly costs are calculated using the following formula: ${ }^{39}$

$$
C(t)=r * K+r * T C+W(t) * 1.25,
$$

where $K$ is the total capital cost, $T C$ is the total training cost, $W(t)$ represents the sum of teachers' wage at date $t$, and $r$ is the real interest rate (discount rate). Finally, I present the cost-benefits analysis for two different assumptions about the deadweight burden of taxation (0.2 and 0.6). 
Further assumptions are needed to compute the yearly benefits of the program. First, an important assumption is that the increase in wages attributed to the program represents an increase in the productivity of labor (and that there is no general equilibrium effects on the returns to education). Second, I estimated the effect of the program on men who work for a wage. I assume that the effect is the same on (working) women and on self-employed people. I also assume that the share of total labor income going to people of any given age is constant across years and is equal to the share of total wages going to this cohort in 1995 (which I can calculate from my data). Thus, I estimate the benefit of the program at date $t$, for a cohort $c$ using the following formula:

$$
B(c, t)=\alpha * G D P(t) * S(c, t) * E(c),
$$

where $\alpha$ is the share of labor in GDP, $S(c, t)$ is the fraction of total wages earned by cohort $c$, in year $t$, and $E(c)$ is the estimated average effect of the program on cohort $c$. It is 0 for people 13 or older in 1974 (they were not exposed to the program). For people aged 2 to 12 in 1974, the effect is given by the coefficients in table 4, multiplied by the average intensity of the program. For the following cohorts, I assume that the effect of the program decreases at the rate of population growth. ${ }^{40}$ To obtain the total benefits for each year, I take the sum of these benefits over all cohorts.

In figure 11, I show the annual costs and benefits of the program from 1973 to 2060, evaluated in millions of 1990 U.S. dollars. The assumptions for this picture are a GDP growth of 2 percent after 1996, a deadweight burden of 0.2 , and a discount rate of 5 percent. The estimates of the program effect are those from table 4, column 5. Benefits are very low from 1973 to 1987 because the generations exposed to the program have not yet entered the job market. After 1989, benefits increase rapidly: each year, a new cohort exposed to the program enters the job market. After 2015, when the generation exposed to the program starts leaving the job market, annual benefits decrease until they reach 0 by 2050 (when the last cohorts educated in these schools leave the job market). Costs increase rapidly from 1973 to 1979, as more schools are built and more teachers need to be paid. Once the total stock is built, costs increase only as teachers' salaries grow. In 1995, when the schools are closed, the costs fall to a very low level corresponding to the annuity payment on initial capital expenditures. In 1996, benefits exceed 
costs.

The relevant variable for the cost benefit calculation is the discounted sum of net benefits at infinity (defined as the difference between yearly benefits and yearly costs). Figure 12 plots this series (discounted from 1973) as a fraction of 1973 GDP. From 2005 on, the discounted sum of net benefits is positive and increases rapidly. The program's compounded net benefits in 2050 reach 18 percent of 1973 's GDP. ${ }^{41}$ The program requires more than thirty years to yield positive returns, but these returns are high.

In table 8, I present an evaluation of the program's returns for the first two specifications estimated in table 4 and three different assumptions about the growth rate of the GDP from 1996 to 2050. I present the discounted sum of program benefits in millions of 1990 U.S. dollars as a fraction of 1973 GDP and as a fraction of costs (calculated by dividing the discounted sum of the program by the cost of the construction of the new buildings and training of the new teachers). To evaluate the contribution of economic growth to the benefits of the program, I also present these results with the assumption that Indonesia's GDP grew at a rate of 2 percent annually from 1973 to 2050 .

The cost-benefits analysis is sensitive to the specification chosen for the estimation of the program effect and to the assumptions about future growth rates in Indonesia. Nevertheless, three main points emerge from this analysis. First, a school construction program takes a very long time to generate positive returns (because the costs are incurred early on, while the benefits are spread over a generation's lifetime). Second, the returns generated are large. By 2050, in the smallest estimate, the program will have generated nine times as much revenue as its initial cost. Third, the benefits are to a large extent driven by the rapid growth of Indonesia's GDP from 1973 to 1997 (which results from the fact that each year's benefits are a fraction of that year's GDP). If the growth rate had been very low from 1973 until today, the net present value of the program would actually have been slightly negative, according to all specifications but one. Therefore, this program is justified ex post. Investing in education is much more valuable, from a government point of view, if it expects a fast subsequent growth. ${ }^{42}$

The last three lines in table 8, panel A indicate the internal rate of return of the program (the interest rate such that the net present value is 0). Using the actual GDP growth between 1973 and 1997, they range from 8.8 percent to 12 percent, depending on the specification and 
hypothesis chosen. These numbers are high, but reasonable. The evidence, therefore, suggests that the program was a profitable investment, with an internal rate of returns substantially higher than the average interest rate on government debt in Indonesia over the period. The profitability of this investment would have been much less obvious if Indonesia's economic growth had been slower.

\section{Conclusion}

The INPRES program of primary school construction led to an increase in educational attainment in Indonesia. The estimates of the effect of the program on the education of children aged 2 to 6 in 1974 range from 0.12 to 0.19 years for each new school built per 1,000 children. In particular, it has encouraged a significant proportion of the population to complete more years of primary education. This increase has translated into an increase in wages of 1.5 to 2.7 percent for each additional school built per 1,000 children. Estimates of economic returns to education using this exogenous variation in schooling (assuming that the program had no other effect than to increase the quantity of education) range from 6.8 percent to 10.6 percent. These numbers can be interpreted as weighted averages of returns to basic education for people who are affected by the instruments, a group that is likely to include the poorest segment of the population.

The findings reported here are important because they show that, in Indonesia, an unusually large government-administered intervention has been effective in increasing both education and wages. This intervention was meant to increase the quantity of education (measured, in the INPRES instructions, by enrollment rates). It is sometimes feared that the deterioration in the quality of education that could result from this type of program could offset any gain in quantity. However, the program was effective in increasing not only education levels, but also wages. This suggests that the combined effect of quality and quantity changes in education was to increase human capital. I presented some evidence that the quality of education does not seem to have deteriorated significantly because of the program. But even if it has, the effect on wages shows that this decline was not sufficient to offset the impact of the increase in quantity.

I presented evidence in favor of the internal validity of these results. I have shown that changes between cohorts were not systematically different in low- and high-program regions before the program started, and I have tried to control for the two variables (the water and 
sanitation program and the enrollment rate in 1971) whose omission was most likely to bias the estimates. It remains possible that these results cannot be generalized to different situations. In particular, the emphasis on education in Indonesia at the time of the program created a context particularly favorable to its success.

The cost-benefits analysis suggests that the cost of the program was smaller than the discounted lifetime gains in the wages of the generation who were exposed to it. It should be noted, however, that this alone does not tell us that the policy should have been implemented or financed by the government. To answer this question, we need to determine whether the levels of education would have been below the social optimum in the absence of the program. This would be the case if altruism were imperfect within the family (so that parents, who in practice make educational choices, do not extract the full benefit of it), if households were facing credit constraints, or if there were positive spillovers of education. Answering these questions is beyond the scope of this paper, but future research could use the variations in education induced by the INPRES program to estimate the impact of education on other outcomes (fertility and child health for example). Future research could also address the question of the social returns to education by examining whether the income of the cohorts not exposed to the program increased faster over time in regions where the program caused increases in the education of the younger cohorts. 


\section{References}

Ahn, Hyungtaik and James L. Powell, "Semi-Parametric Estimation of Censored Selection Model with a Non-Parametric Selection Mechanism," Journal of Econometrics, 1993, 58, $3-29$.

Angrist, Joshua D., "Conditioning on the Probability of Selection to Control Selection Bias," Technical Working Paper 181, National Bureau of Economic Research 1995.

_ , "The Economic Returns to Schooling in the West Bank and Gaza Strip," American Economic Review, 1995, 85 (5), 1065-1087.

and Guido Imbens, "Identification and Estimation of Local Average Treatment Effects," Econometrica, 1994, 62 (2), 467-475.

_ and _ _ , "Two Stage Least Squares Estimation of Average Causal Effects in Models with Variable Treatment Intensity," Journal of the American Statistical Association, 1995, 90, 431-442.

and W.N. Evans, "Schooling and Labor Market Consequences of the 1970 State Abortion Reform," Working Paper 5406, National Bureau of Economic Research 1996.

Ashenfelter, Orley, Colm P. Harmon, and Hessel Oosterbeek, "Empirical Estimation of the Schooling/Earnings Relationship - A Review," 1998. Mimeo, University College Dublin.

Bappenas, Pedoman Pelaksanaan Bantuan Pembagunan Sekolah Dasar Menurut Instruki Presiden Republik Indonesia 1973, 1974, 1975, 1976, 1977, 1978.

Becker, Gary, Human Capital and the Personal Distribution of Income, Ann Arbor, Michigan: University of Michigan Press, 1967.

Behrman, Jere R., "The Action of Human Resources and Poverty on One Another," Working Paper 74, Living Standards Measurement Studies 1990.

and Anil B. Deolalikar, "School Repetition, Dropout and the Returns to Schooling: the Case of Indonesia," Oxford Bulletin of Economics and Statistics, 1991, 53 (4), 467-480. 
and __ , "Unobserved Household and Community Heterogeneity and the Labor Market Impact of Schooling: A Case Study of Indonesia," Economic Development and Cultural Change, 1993, 41, 461-488.

and Nancy Birdsall, "The Quality of Schooling: Quantity Alone is Misleading," American Economic Review, 1983, 73, 928-946.

Bils, Mark and Peter Klenow, "Does Schooling Cause Growth or the Other Way Around?," Working Paper 6393, National Bureau of Economic Research 1998.

Birdsall, Nancy, "Public Inputs and Child Schooling in Brazil," Journal of Development Economics, 1985, 18 (1), 67-83.

Butcher, Kristin F. and Anne Case, "The Effect of Sibling Sex Composition on Women's Education and Earnings," Quarterly Journal of Economics, 1994, 109 (3), 531-563.

Card, David, "Using Geographic Variation in College Proximity to Estimate the Returns to Schooling," Working Paper 4483, National Bureau of Economic Research 1993.

_ _ , "Earnings, Schooling and Ability Revisited," in S. Polachek, ed., Research in Labor Economics, Greenwich, CT: JAI Press, 1995.

_ , "The Casual Effect of Education on Earnings," in Orley Ashenfelter and David Card, eds., Handbook of Labor Economics, North Holland, 1999.

_ and Anne Krueger, "Does School Quality Matter? Returns to Education and the Characteristics of Public Schools in the United States," Journal of Political Economy, 1992, $100(1), 1-40$.

and Thomas Lemieux, "Earnings, Education and the Canadian GI Bill," 1998. Mimeo, University of California at Berkeley.

Case, Anne and Angus Deaton, "School Quality and Educational Outcomes in South Africa," 1996. Mimeo, Research Program in Development Studies, Princeton University.

Daroesman, Ruth, "Finance of Education," Bulletin of Indonesian Economic Studies, 1971, $7(3), 61-95$. Parts 1 and 2. 
DeTray, Dennis, "Government Policy, Household Behavior and the Distribution of Schooling: A Case Study of Malaysia," in T.P. Schultz, ed., Research in Population Economics, Vol. 6, Greenwich, CT: JAI Press, 1988.

Foster, Andrew D. and Mark R. Rosenzweig, "Technical Change and Human-Capital Returns and Investments: Evidence from the Green Revolution," American Economic Review, 1996, $86(4), 931-953$.

Garg, Ashish and Jonathan Morduch, "Sibling Rivalry," 1997. Mimeo, Princeton.

Gertler, Paul and John W. Molyneaux, "How Economic Development and Family Planning Programs Combined to Reduce Indonesian Fertility," Demography, 1994, 31 (1), 33-63.

Glewwe, Paul and Hanan Jacoby, "An Econometric Analysis og Delayed Primary School Enrollment and Childhood Malnutrition in a Low Income Country," Review of Economics and Statistics, 77 (1), 156-169.

Griliches, Zvi, "Estimating the Returns to Schooling: Some Econometric Problems," Econometrica, 1977, 45, 1-22.

_ _ "Sibling Model and Data in Econometrics: Beginnings of a Survey," Journal of Political Economy, 1979, 8\%, S37-S64.

Heckman, James J., "Comments to Nada Eissa," in M. Feldstein and J. Poterba, eds., Empirical Foundation of Household Taxation, Chicago: University of Chicago Press, 1996.

and V. Joseph Hotz, "Choosing Among Alternative Non Experimental Methods for Estimating the Impact of Social Programs: the Case of Manpower Training," Journal of the American Statistical Association, 1989, 84 (408), 862-874.

, Lance Lochner, and Christopher Taber, "General Equilibrium Treatment Effects: A Study of Tuition Policy," Working Paper 6426, National Bureau of Economic Research 1998.

Heneveld, Ward, "The Distribution of Development Funds: New School Building in East Java," Bulletin of Indonesian Economic Studies, 1978, 14 (1), 63-79. 
Hill, Hal, The Indonesian Economy Since 1966: Southeast Asia's Emerging Giant, Cambridge: Cambridge University Press, 1996.

Hungerford, Thomas and Gary Solon, "Sheepskin Effects in the Returns to Education," Review of Economics and Statistics, 1987, 69, 175-177.

Jaeger, David A. and Marianne E. Page, "Degrees Matter: New Evidence on Sheepskin Effects in the Returns to Education," Review of Economics and Statistics, 1996, 78 (4), $733-739$.

Kane, Thomas J. and Cecilia E. Rouse, "Labor Market Returns to Two- and Four-year College," American Economic Review, 1995, 85 (3), 600-614.

Lang, Kevin, "Ability Bias, Discount Rate Bias, and the Returns to Education," 1993. Mimeo, Boston University.

— and David Kropp, "Human Capital versus Sorting: the Effects of Compulsory Attendance Laws," Quarterly Journal of Economics, August 1986, pp. 609-624.

Lavy, Victor, "School Supply Constraints and Children's Educatonal Outcomes in Rural Ghana," Journal of Development Economics, 1996, 51 (2), 291-314.

Lillard, Lee A. and Robert J. Willis, "Intergenerational Educational Mobility: Effects of Family and State in Malaysia," Journal of Human Resources, 1994, 29 (4), 1126-1166.

Maluccio, John, "Endogeneity of Schooling in the Wage Function: Evidence from Rural Philippines," 1998. Mimeo, International Food Policy Research Institute.

Meyer, Bruce D., "Natural and Quasi-experiments in Economics," Journal of Business, Economics and Statistics, 1995, 13 (2), 151-161.

Pitt, Mark, Mark Rosenzweig, and Donna Gibbons, "The Determinants and Consequences of Placement of Government Programs in Indonesia," World Bank Economic Review, 1993, 7, 319-348.

Psacharopoulos, George, Returns to Education: an International Comparison, San Francisco: Jossy Bass-Elsevier, 1973. 
_ _ "Returns to Education: an Updated International Comparison," Comparative Education, $1981,17,321-341$.

_ _ "Returns to Education: a Further International Update and Implications," Journal of Human Resources, 1985, 20 (4), 583-604.

_ _ , "Returns to Investments in Education: a Global Update," World Development, 1994, 22 (9), 1325-1343.

Ravallion, Martin, "INPRES and Inequality: a Distributional Perspective on the Center's Regional Disbursements," Bulletin of Indonesian Economic Studies, 1988, 24 (3), 53-70.

Rosenbaum, Paul R., "The Role of a Second Control Group in an Observational Study," Statistical Science, 1987, 3, 292-306.

Rosenzweig, Mark R. and Kenneth I. Wolpin, "Evaluating the Effects of Optimally Distributed Programs: Child Health and Family Planning Interventions," American Economic Review, 1988, 76 (3), 470-482.

_ and _ _ , "Migration Selectivity and the Effects of Public Programs," Journal of Public Economics, 1988, 37, 265-289.

Strauss, John and Duncan Thomas, "Human Resources: Empirical Modeling of Household and Family Decisions," in Jere Behrman and T.N. Srinivasan, eds., Handbook of Development Economics, Vol. 3, Amsterdam: North Holland, 1995, chapter 34, pp. 1885-2023. and __ , "Wages, Schooling and Background: Investments in Men and Women in Urban Brazil," in N. Birdsall and Richard H. Sabot, eds., Opportunity Foregone: Education in Brazil, Washington, DC: World Bank, 1997.

World Bank, "Indonesia: Basic Education Study," World Bank Report 7841-IND, Washington, DC 1990.

__ , "Indonesia: Poverty Assessment," Technical Report, Washington, DC 1990. 


\section{Notes}

* Massachusetts Institute of Technology. Department of Economics. 50 Memorial Drive. Cambridge MA 02142. Financial support from the Fondation Thiers and the Alfred P. Sloan Dissertation Fellowship is gratefully acknowledged. I also thank the World Bank for partially funding this research, the Central Bureau of Statistics of Indonesia, the Bappenas and the Ministry of Education and Culture for data, and the staff of the HIID office in Jakarta (in particular Joe Stern and Peter Rosner) for their help and hospitality. I am grateful to Joshua Angrist, Abhijit Banerjee, Michael Kremer, and Jonathan Morduch for their advice and support throughout this research, and to Daron Acemoglu, David Card, Anne Case, Aimee Chin, Angus Deaton, Guido Imbens, Emmanuel Saez, various seminar participants, and two referees for helpful comments. I bear sole responsibility for the content of this paper, which is not meant to reflect the views of the World Bank or any government agency.

${ }^{1}$ Kristin F. Butcher and Anne Case (1994) use sibling composition as an instrument for women's education in the United States. Ashish Garg and Jonathan Morduch (1998) find that sibling composition affects education in poor households in Ghana, but they also find evidence of an impact of sibling composition on health, which is likely to affect income directly.

${ }^{2}$ Maluccio (1998) uses a sample of 250 wages earners in the Philippines and relies on distance to school reported by the parents in 1978 as an instrument for education of the individuals interviewed in 1994.

${ }^{3}$ The matching was complicated by the fact that some districts changed boundaries or name. I used maps of Indonesia to resolve these ambiguities.

${ }^{4}$ This share does not include teachers' salaries, which are paid out of the routine component of the budget.

${ }^{5}$ The program did not stop at that date. I chose to consider the construction between 1973 74 and 1978-79 for the following reasons: it corresponds to the duration of the second five-year plan, a very high primary enrollment rate was achieved in 1978, and people born in 1972 (the 
youngest cohort in my sample) turned 7 in 1979 and were therefore fully exposed to the program. The program slowed down considerably after 1978-79.

${ }^{6} \mathrm{I}$ chose 1971 as a base year for the population of children because 1971 was a census year. In census publications, the district population is broken down by wide age categories, so I have to use children aged 5-14 as the reference group,instead of children aged 7-12.

${ }^{7}$ The transmigration regions are the areas where the government of Indonesia encouraged new settlement as a solution to the overcrowding of Java.

${ }^{8}$ The 1971 census publications do not give enrollment rates among children aged 7 to 12 , but only the fraction of the overall population attending school.

${ }^{9}$ To correct for measurement error in enrollment rates, I use an uncorrelated measure of regional education as an instrument for enrollment rate in the population in 1971: the average education of individuals born between 1950 and 1960 .

${ }^{10}$ Age at school entry varies in developing countries (Paul Glewwe and Hanan Jacoby (1995)) and grade repetition is important in Indonesia (Jere R. Behrman and Anil B. Deolalikar (1991)). In table 1, panel C, I show information from the Indonesian Family Life Survey (IFLS) data set: 20 percent of children have repeated at least one grade. I estimated the number of people still attending primary school after age 12 and 13 in the IFLS, by combining information of age when the individual left school with the information about grade repetition. At age 13 or above 16 percent of students were still in primary school, but only 7 percent were still in primary school a year later.

${ }^{11}$ If I had data on region of education, I could use region of birth as an instrument for region of education.

${ }^{12}$ To make Wald estimates meaningful, estimates in table 3 are presented for the sample with valid wage data. High program regions are defined as regions where the residual of a regression of the number of schools on the number of children is positive.

${ }^{13}$ See Rosenzweig and Wolpin (1988a), Pitt, Rosenzweig and Gibbons (1993), Gertler and Molyneaux (1994). 
${ }^{14}$ James J. Heckman, Lance Lochner and Christopher Taber (1998) make this point in their analysis of the effects of tuition policy in the United States.

${ }^{15}$ Card (1995) assumes concave returns to schooling. I abstract from this to focus on the most important assumptions underlying the identification strategy in this context.

${ }^{16}$ See Joshua Angrist (1995b) for an analysis of general equilibrium effects of a rapid increase in education, Jere R. Berhman and Nancy Birdsall (1983) and Card and Krueger (1992) for the impact of school quality on returns to education and Andrew D. Foster and Mark R. Rosenzweig (1996) for the influence of economic growth on returns to education.

${ }^{17}$ This implies that $S_{j}=1 / 2\left(S_{j 0}+S_{j k}\right)$. Extending the calculations to several cohorts is conceptually easy but makes notation cumbersome.

${ }^{18}$ Using equation (2) and imposing the assumption that the old cohort did not anticipate the program, I obtain $E_{0} S_{j k}=E_{0} S_{j 0}-\frac{D_{1}}{\phi}$, where $D_{1}=E_{0}\left(\mu_{j k}-\mu_{j 0}\right)$. Replacing this in the expected value of equation (4) and substituting $E_{0} b_{j 0}$ in equation (2), I obtain $\left(\phi-2 \beta_{1}\right) S_{j 0}=$ $-\alpha_{1} Z_{j 0}+\beta_{3} q_{j 0}+2 \beta_{2} E_{0} \bar{S}+D_{2}$ with $D_{2}=E_{0} v_{j}-\frac{\beta_{1} D_{1}}{\phi}-\mu_{j 0}$. I can then combine this with equation (2) to obtain $\left(\phi-\beta_{1}\right)\left(S_{j k}-S_{j 0}\right)=-\alpha_{1}\left(Z_{j k}-Z_{j 0}\right)+\beta_{3}\left(q_{j k}-q_{j 0}\right)+2 \beta_{2}\left(E_{k} \bar{S}-E_{0} \bar{S}\right)+D_{3}$, with $D_{3}=E_{k} v_{j}-E_{0} v_{j}-\left(\mu_{j k}-\mu_{j 0}\right)+\frac{\beta_{1} D_{1}}{\phi}$

${ }^{19}$ The potential decline in the returns to education in regions that received more schools affects all cohorts, whether or not they were exposed to the program. Therefore, I will observe a (spurious) negative relationship between $y_{j k}-y_{j 0}$ and the program for $k>13$.

${ }^{20}$ This is equivalent to a weighted least squares estimation of equation (6).

21 The number of schools per child was negatively correlated with the number of children, and I want to abstract from any time-varying effect of region population. It turns out to be important in the wage equation.

${ }^{22}$ Reverse causality (improvement in performance causing improvement in inputs) is not a potential problem in this case (unlike in Gertler and Molyneaux (1994) and in Pitt et al. (1993)), because during the entire period, the allocation rule was explicitly based upon enrollment in 1972 (i.e., before the INPRES program). 
${ }^{23}$ Using enrollment in primary schools in 1973 divided by children's population gives similar results, but this variable is available for fewer provinces than the enrollment rate in 1971. I also ran the same regressions controlling in addition for average education in the cohort 1950-1960 (which corresponds more closely to the framework outlined in section III), and found similar results.

${ }^{24}$ I have plotted the coefficients corresponding to the specification in table A1, column 2.

${ }^{25}$ The government may care more about those children who, in the absence of the program, would have had the least education. However, I cannot really answer this question by examining how the distribution of education is affected by the program (because the difference in quantiles is not the quantile of the difference).

${ }^{26}$ The shape of this function is not affected by controlling for interactions of enrollment rate (or water and sanitation program) and year-of-birth dummies.

${ }^{27}$ The negative difference in differences at the senior high school level may indicate that some variable predicting the probability of attending senior high school is omitted from this regression (and changed in low-program regions more than in high program regions).

${ }^{28}$ For example, Angrist and Imbens (1995) find that compulsory attendance laws in the United States induce a fraction of the sample to complete some college as a consequence of constraining them to complete high school.

${ }^{29}$ I have also estimated this equation using LIML, which is median unbiased and does not suffer from this problem. LIML results are very similar to 2SLS results, providing evidence that the weak instruments problem is not serious in this application.

${ }^{30}$ For example, in a study on returns to education in Indonesia, Behrman and Anil B. Deolalikar (1993) introduce household fixed effects in an earnings function and report estimates that are much lower than the corresponding OLS estimates. Note, however, that introducing fixed effects into a wage equation reduces the sample size and might exacerbate the attenuation bias due to measurement errors (Zvi Griliches (1979)).

${ }^{31}$ Note that the OLS coefficients indicate a correlation and are not causal estimates; these 
high coefficients could be an artifact of selection into secondary education.

${ }^{32}$ I have not presented the 2SLS estimate when the F-statistic for the joint significance of the instruments in the first stage was below 2, because it would not be interpretable.

${ }^{33}$ Note that I partition the sample according to education, which is an endogenous variable. It not ideal, but it is not likely to be a real problem in this case, because the decision to go to senior high school is quite different from the decision to complete one more year of primary school.

${ }^{34}$ The data shows that the program reduced pupil/teacher ratios in densely populated regions, which is expected given that it increased the number of teachers but not the number of pupils in these regions. This suggests that pupil/teacher ratios did not have a big impact on effective school quality.

${ }^{35}$ Individuals who did not work at least one hour in the previous week do not report a branch of activity. They are, therefore, still excluded from this sample.

${ }^{36}$ The loss incurred by the older generations, whose returns to education went down because of the program are not taken into account in the reduced form estimates of the program's effects.

${ }^{37}$ More generally, the cost-benefits analysis should ideally be based on the consumer surplus generated by the program. It includes the additional cost for children to go to school as well as the benefits for all children to go to a school that is now closer to their home.

${ }^{38}$ And indeed in 1997, most INPRES schools constructed in the mid-1970's were either closed or crumbling.

${ }^{39}$ The assumption that the government pays an annuity on the capital and training expenditures and pays the wage bill every year is of course irrelevant for the calculation of the discounted sum of net benefits or the internal rate of returns.

${ }^{40}$ So for a cohort born $y$ years after 1972 , the effect would be calculated as $E(c)=\frac{E(72)}{(1+n)^{y}}$ if the population growth rate were constant.

${ }^{41}$ After 2050, the benefits are stable, and I, therefore, consider 2050 as the infinity point. 
${ }^{42}$ A related point is made by Mark Bils and Peter Klenow (1998), who argue that the correlation between growth and education in cross-country growth regressions is likely to be driven by the fact that high expected growth makes investment in education more profitable. 

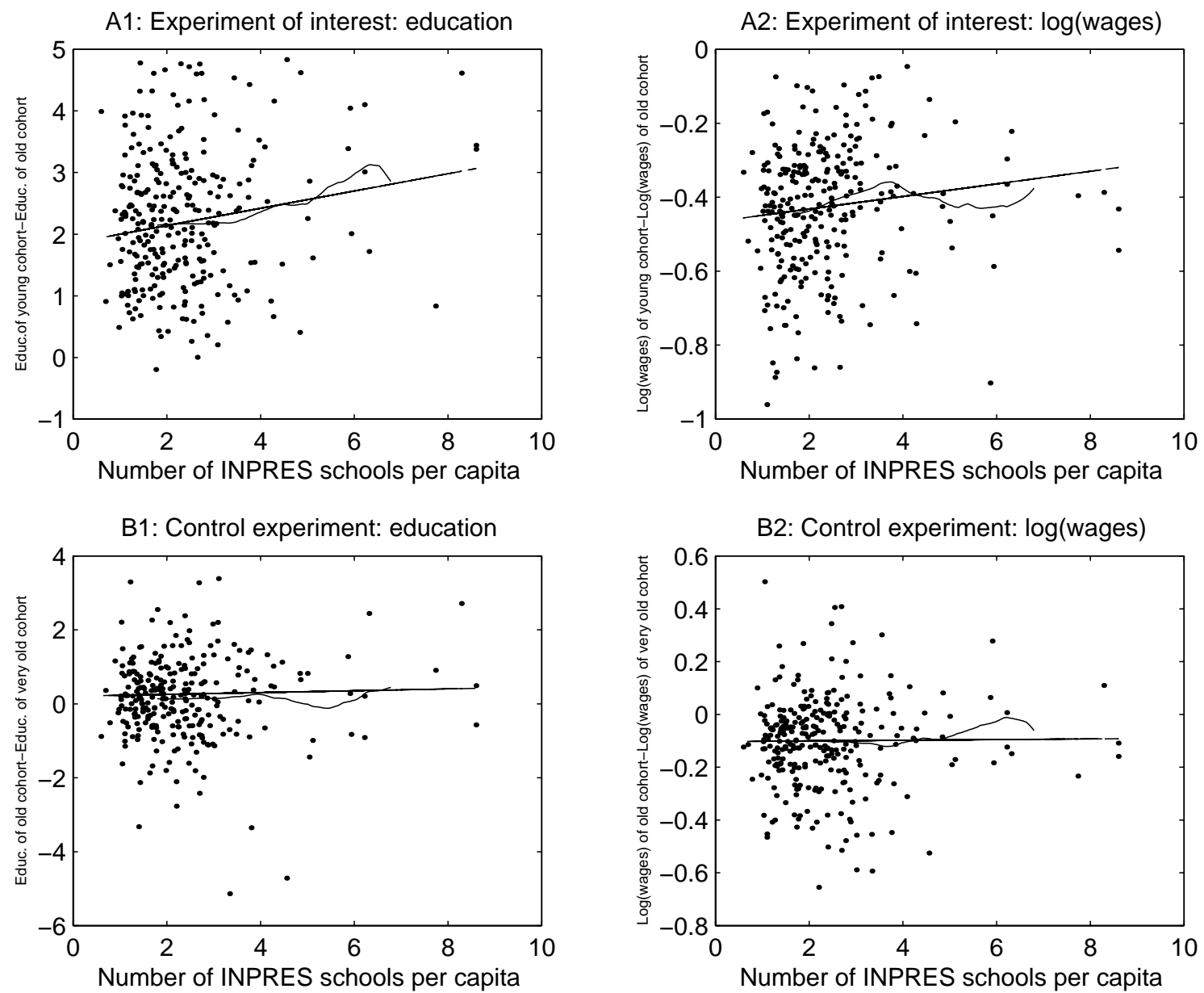

FiguRE 1: Regional growth in education and log wages accross cohort and program intensity (Per capita denotes per 1000 children) 


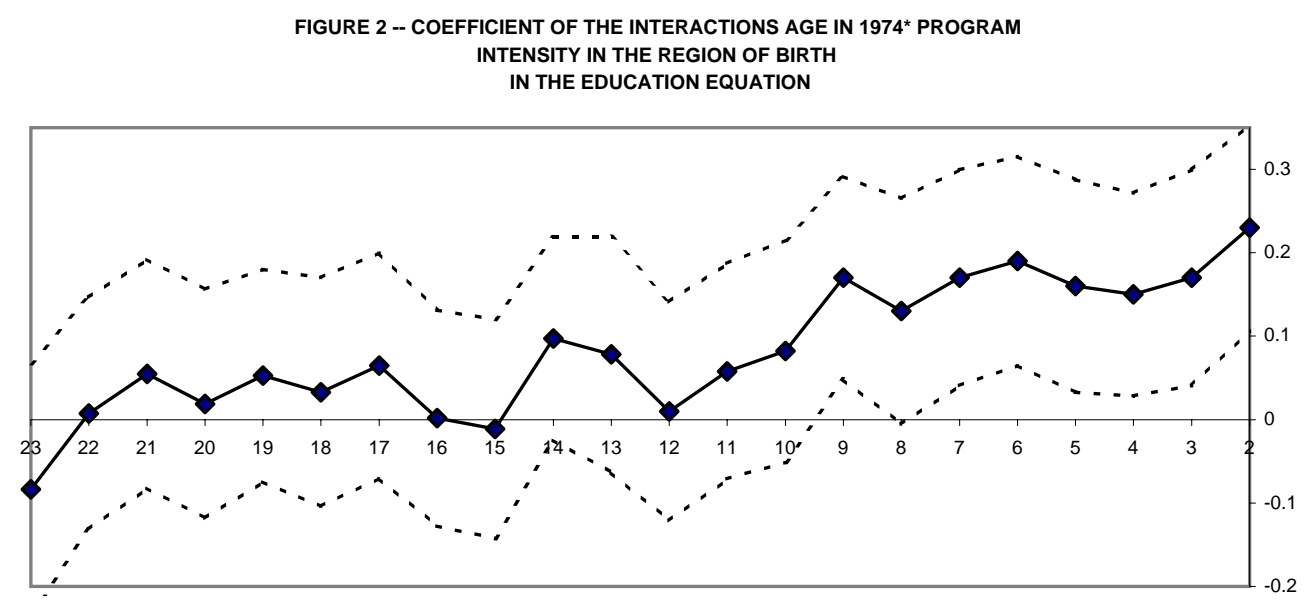

Age in 1974

FIGURE 3A -- COEFFICIENTS OF THE INTERACTION AGE IN 1974^ PROGRAM INTENSITY IN THE REGION OF BIRTH

IN THE WAGE AND EDUCATION EQUATIONS

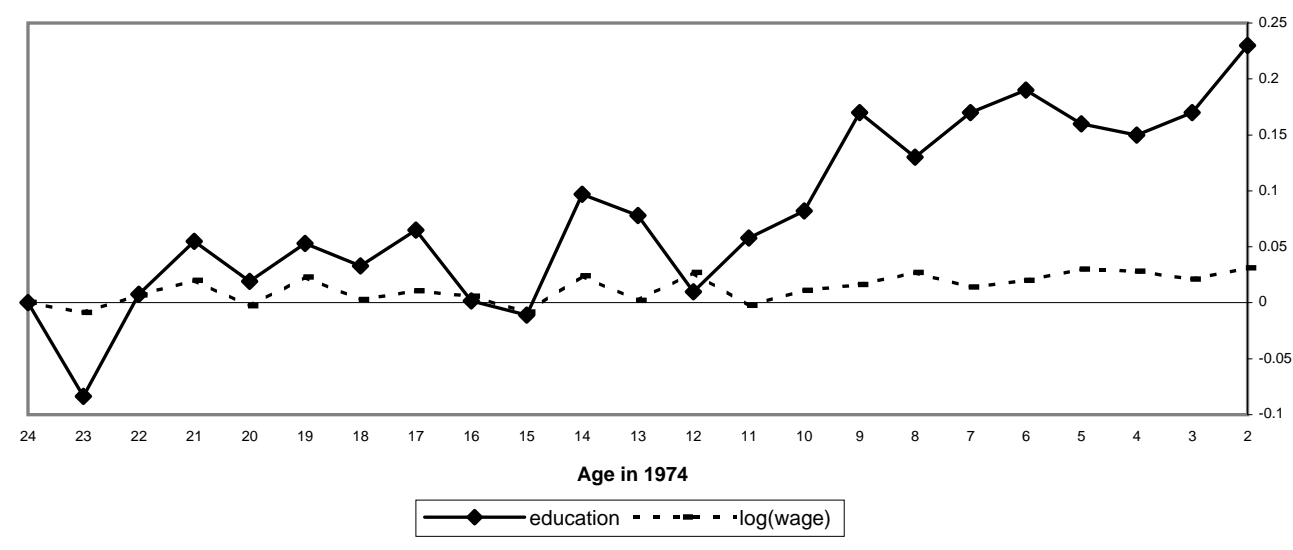

FIGURE 3B -- COEFFICIENTS OF THE INTERACTION AGE IN 1974^ PROGRAM INTENSITY IN THE REGION OF BIRTH

IN THE WAGE AND EDUCATION EQUATIONS (SMOOTHED)

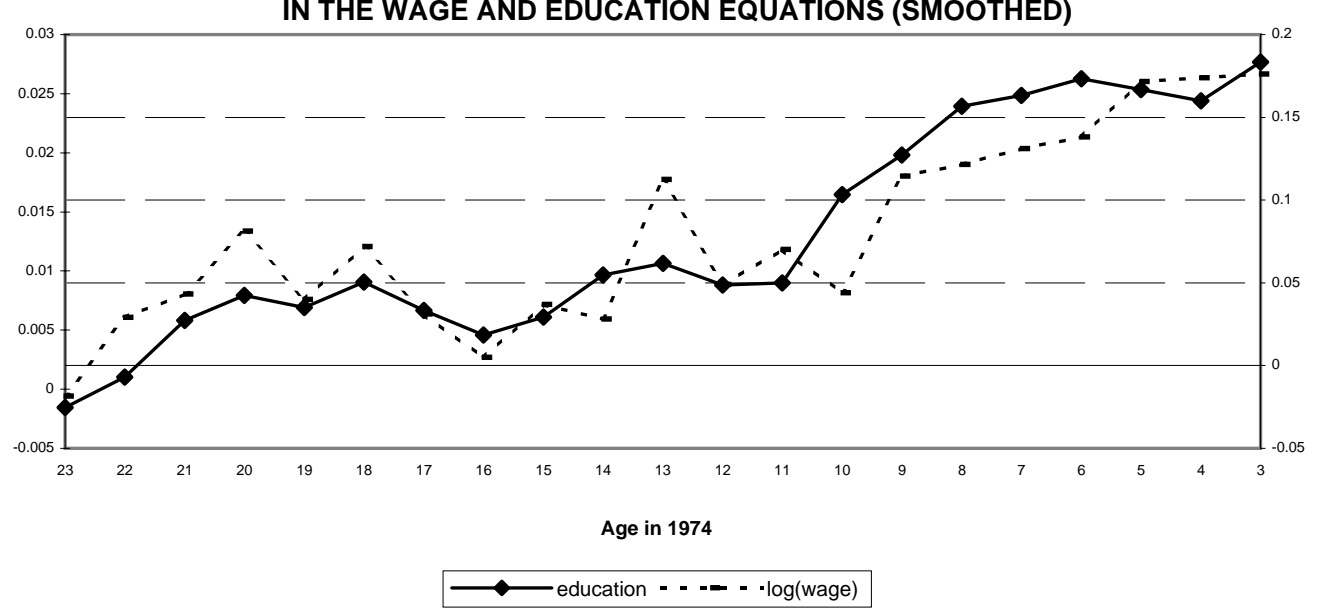



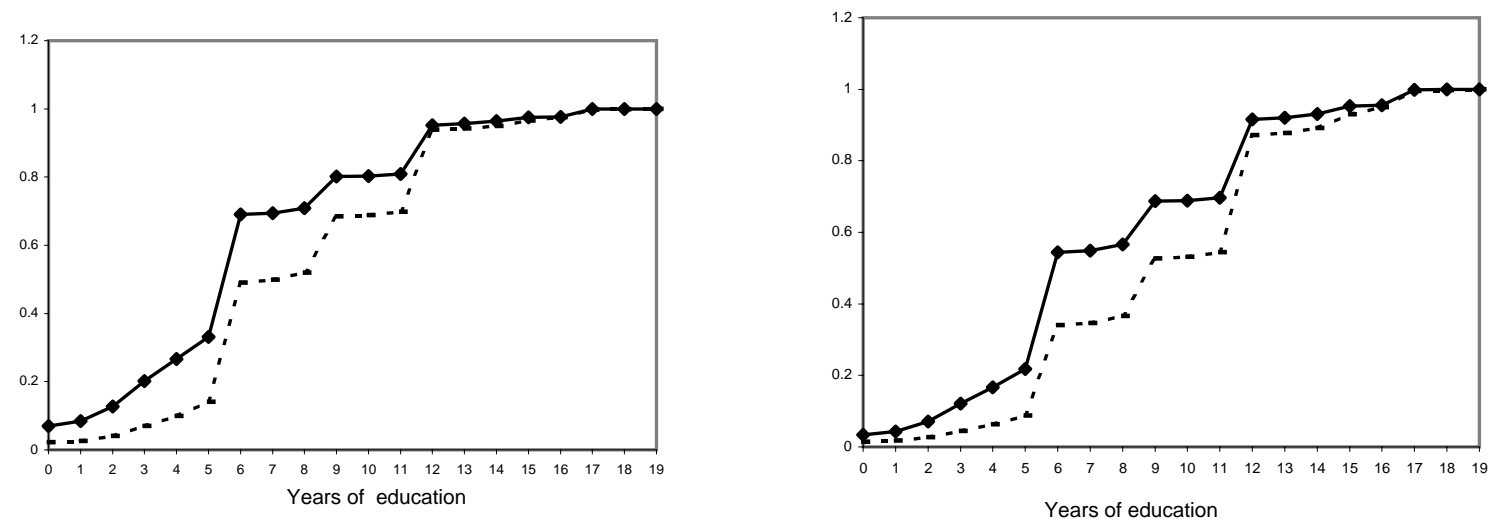

12 to 17 in 1974 - - -.- - 2 to 6 in 1974

FIGURE 6 -- BETWEEN COHORT DIFFERENCES IN CDF OF EDUCATION

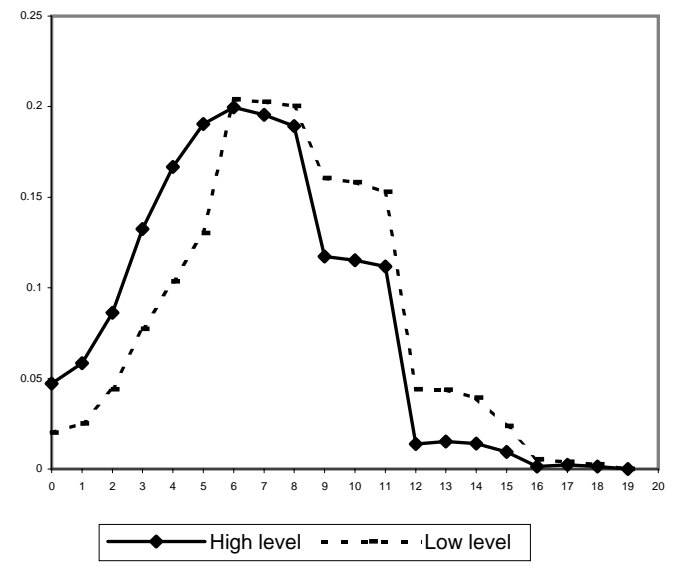

FIGURE 7 -- DIFFERENCE IN DIFFERENCES IN CDF (WITH 95\% CONFIDENCE INTERVAL)

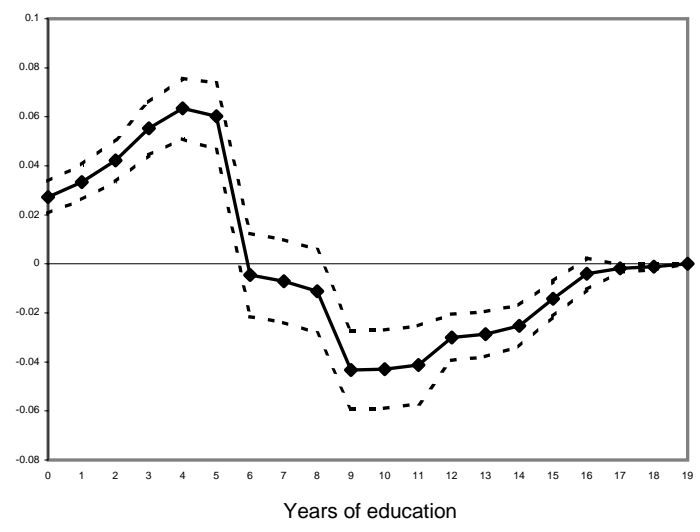

FIGURE 8 -- DIFFERENCE IN DIFFERENCES IN CDF (ESTIMATED FROM LINEAR PROBABILITY MODEL) WITH 95\% CONFIDENCE INTERVAL

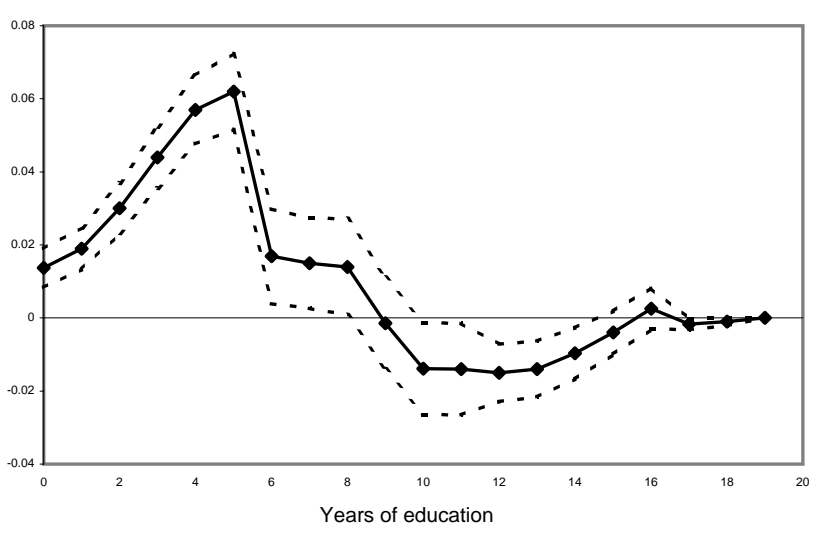


FIGURE 9 -- COEFFICIENTS OF THE INTERACTIONS AGE IN 1974* PROGRAM INTENSITY IN THE REGION OF BIRTH IN THE WAGE AND EDUCATION EQUATION (SAMPLE: INDIVIDUALS WHO COMPLETED MORE THAN 9 YEARS OF EDUCATION)
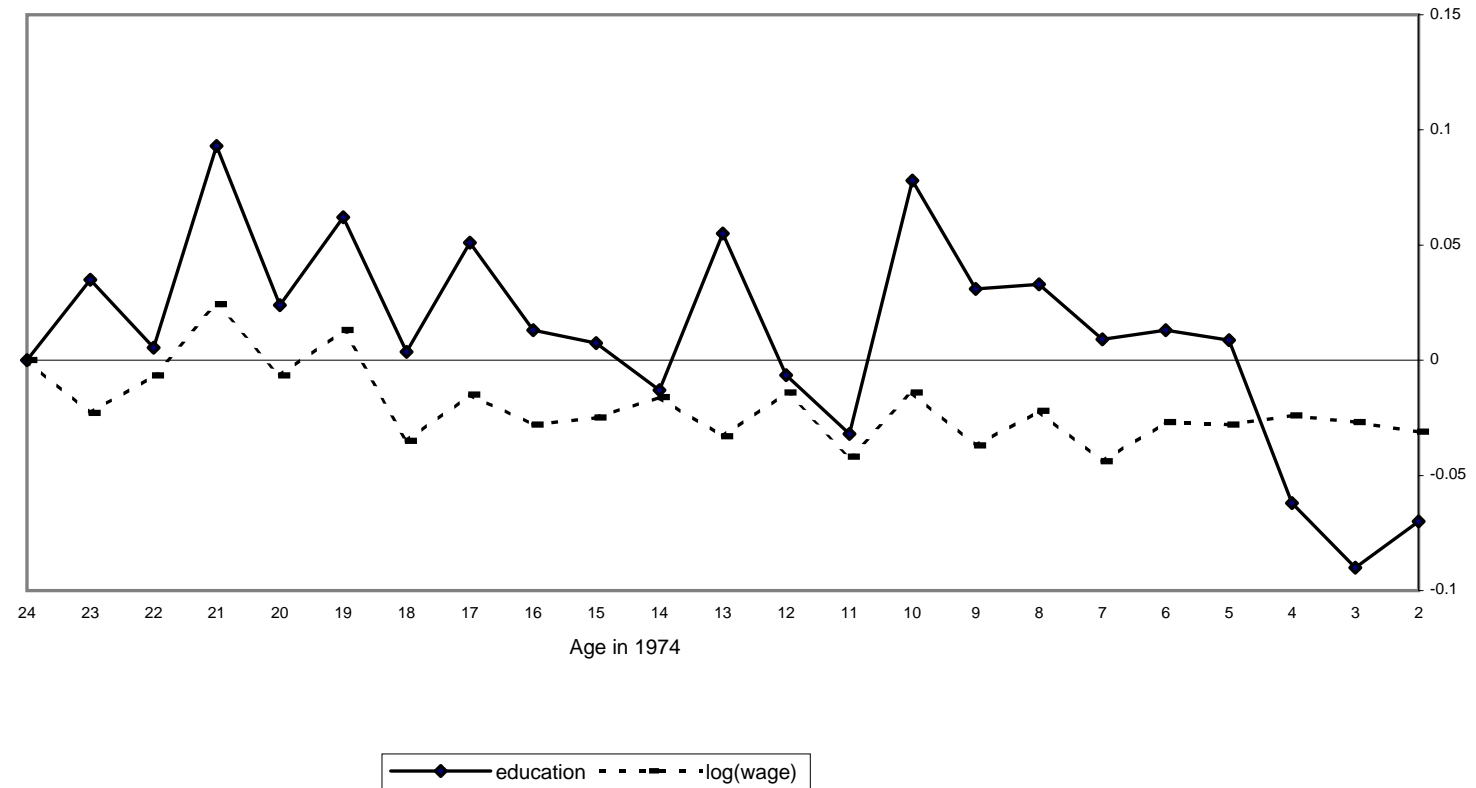

FIGURE 10 -- RETURNS TO EACH YEAR OF EDUCATION (OLS ESTIMATE)

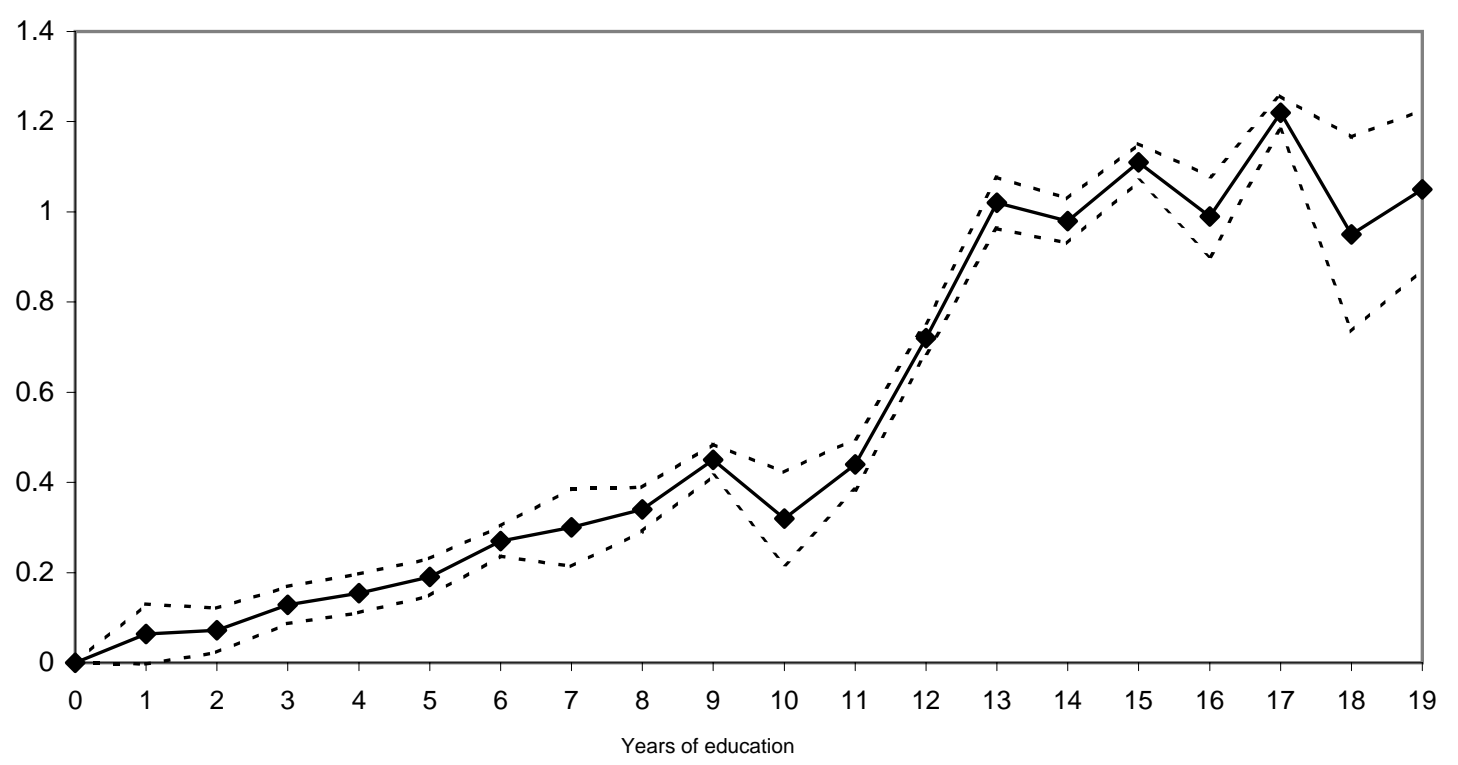




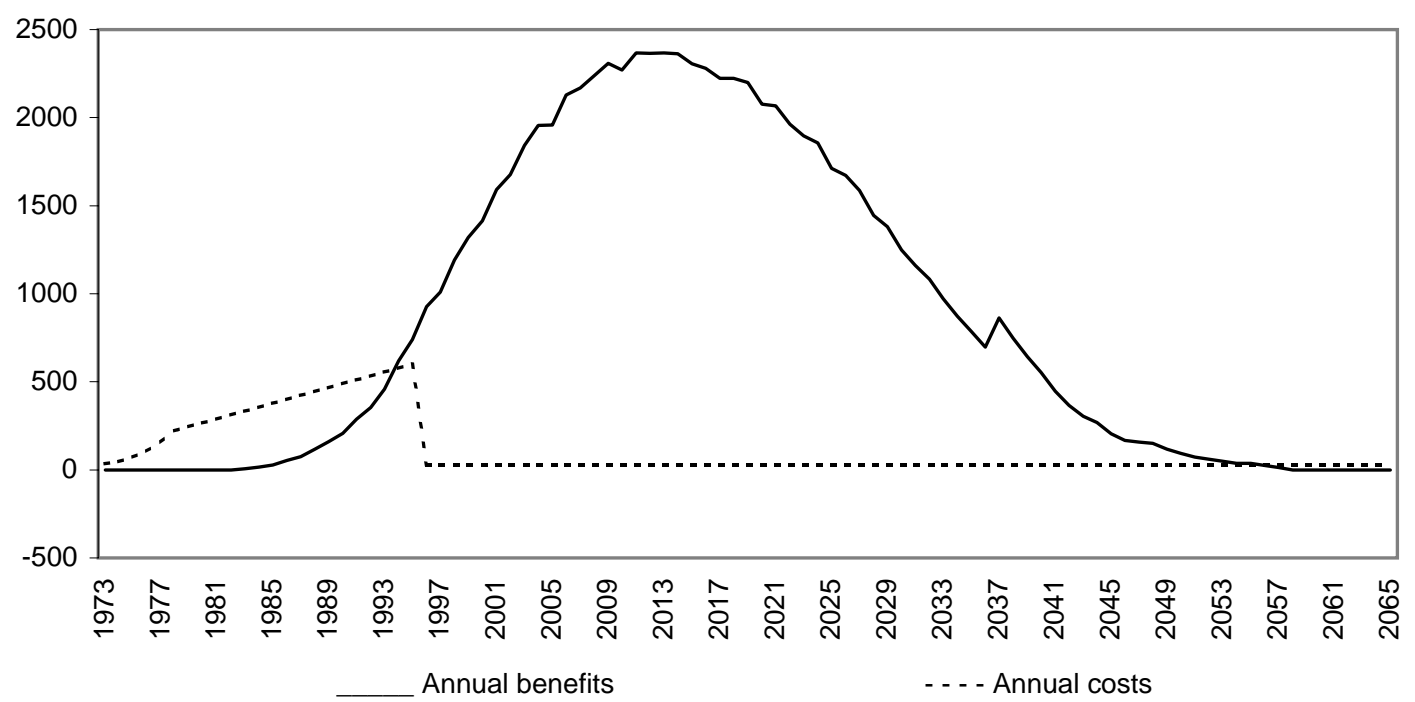

FIGURE 12 -- DISCOUNTED SUM OF PROGRAM'S NET BENEFIT (MILLION 1990 US DOLLARS)

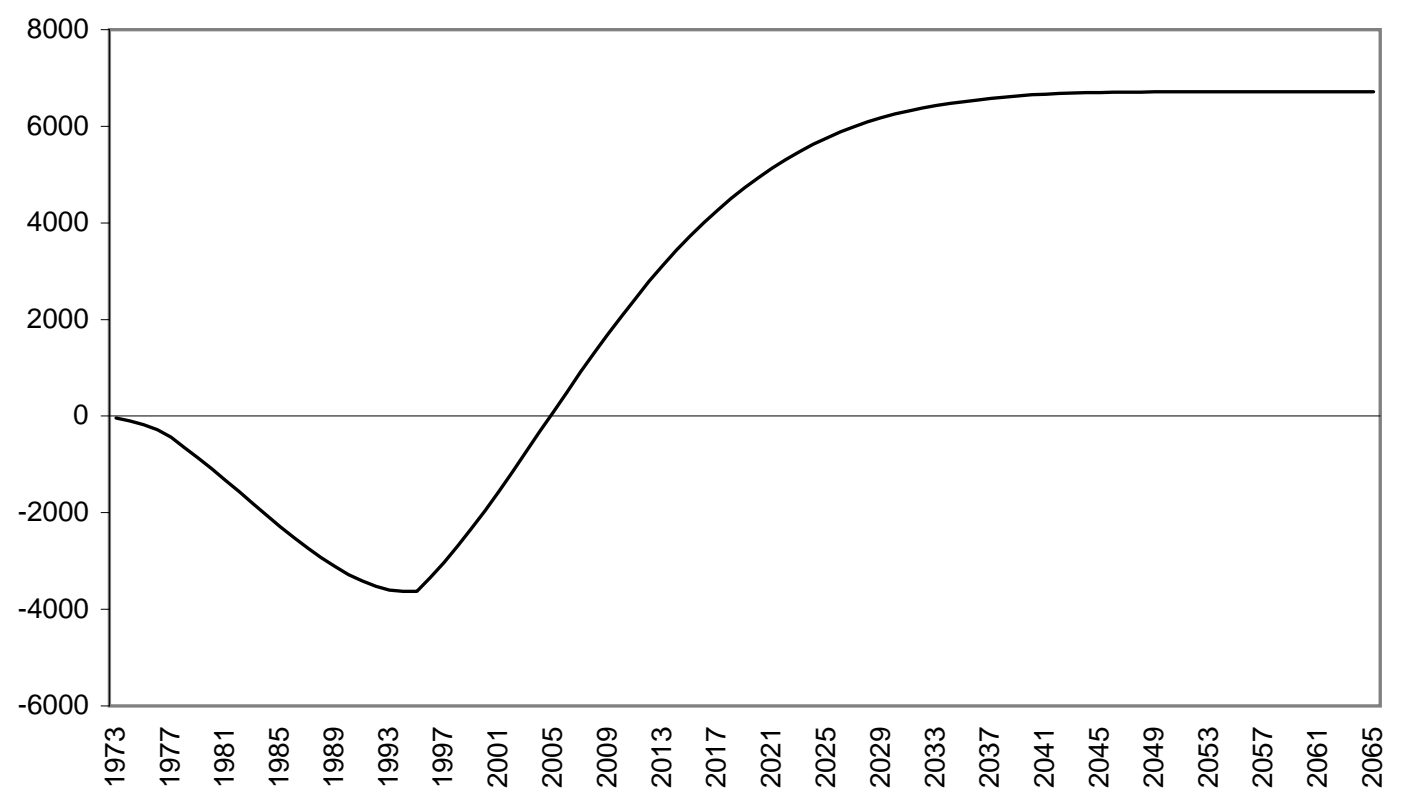

Assumptions: Deadweight burden: 0.2. GDP growth after 1973: 2\%. Program effect is estimated without controlling for enrolment rate (table 5, columns 7). 
TABLE 1 -- DESCRIPTIVE STATISTICS

\begin{tabular}{lr}
\hline \hline & Mean \\
Panel A: Individual Level Means & 7.98 \\
Education (whole sample N=152,989) & 9.00 \\
Education (sample with valid wage data N=60,663) & 1.98 \\
INPRES schools built for 1000 children & 1.89 \\
INPRES schools built for 1000 children (sample with valid wage data) & 2.44 \\
INPRES schools built for 1000 children (High program regions) & 1.54 \\
INPRES schools built for 1000 children (Low program regions) & 6.87 \\
Log(hourly wage) & 13 \\
Monthly earnings (SUPAS 1995),thousands Rupiah & 205 \\
Monthly earnings (SUSENAS 1993) of wage earners, thousands Rupiah & 152 \\
Monthly earnings (SUSENAS 1993) of self-employed individuals, thousands Rupiah &
\end{tabular}

\section{Panel B: District Level Means (N=293)}

INPRES schools constructed (1973/74 - 1978/79)

222

INPRES schools constructed for 1000 children (1973/74 - 1978/79) 2.34

Number of teachers in 1973/74 1530

Number of teachers in 1978/79 2082

Number of schools in 1973/74 $\quad 219$

Fraction of the population attending schools in 1971 (census) 0.174

$\begin{array}{ll}\text { Enrollment rate in primary school in } 1973 \text { (Ministry of education and culture) } & 0.68\end{array}$

\section{Panel C: Indonesian Family Life Survey, Individuals Born Between 1950 and 1972}

(all numbers are in percentage)

Proportion of individuals having migrated between birth and age $12 \quad 8.5$

Proportion of people having repeated at least one grade in primary school 20

Proportion of people completin more than primary having repeated at least one grade in primary school 6.0

Proportion of individuals having attended primary school after age 12 (estimated) $\quad 15.8$

Proportion of individuals having attended primary school after age 13 (estimated) 6.8

Proportion of individuals born 1950-1961, completing primary or less, who left school after 1974

Proportion of individuals born 1962-1966, completing primary or less, who left school after $1974 \quad 24.5$ 
TABLE 2 -- THE ALLOCATION OF SCHOOLS

$\log$ (INPRES schools)

Log of number of children aged 5-14 in the region $\quad 0.78$

Log(1-enrollment rate in primary school in 1973)

0.12

(0.038)

Number of observations $\quad 255$

\begin{tabular}{lc}
$\mathrm{R}$ squared & 0.78 \\
\hline Notes: Standard errors are in parentheses.
\end{tabular}

Notes: Standard errors are in parentheses.

The dependent variable in the log of the number of INPRES schools built between 1973 and 1978.

The enrollment rate in primary school is the number of children enrolled in primary school in 1973 (obtained from the Ministry of education and Culture) divided by the number of children aged 5-14 in the region in 1973 
TABLE 3 -- MEANS OF EDUCATION AND LOG(WAGE) BY COHORT AND LEVEL OF PROGRAM CELLS

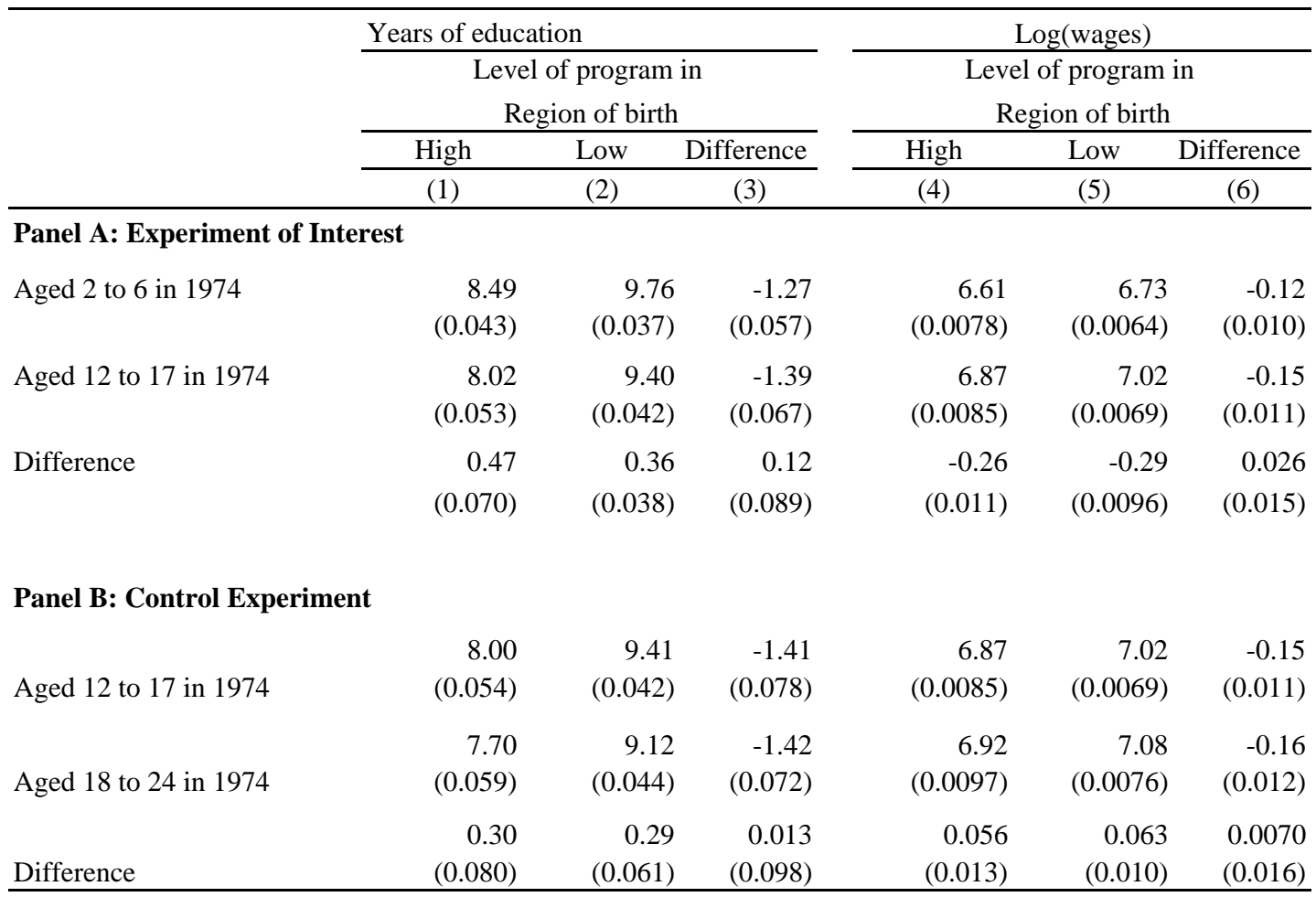

Note: The sample is made of the individuals who earn a wage. Standard errors are in parentheses 


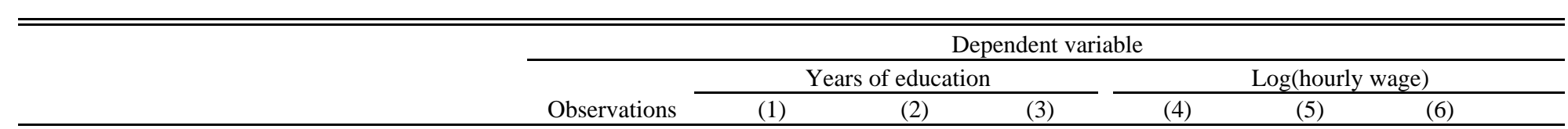

PANEL A: Experiment of Interest: Individuals Aged 2 to 6 or 12 to 17 in 1974

(Youngest Cohort: Individuals Ages 2 to 6 in 1974)

\begin{tabular}{|c|c|c|c|c|c|c|c|}
\hline Whole sample & 78,470 & $\begin{array}{r}0.124 \\
(0.0250)\end{array}$ & $\begin{array}{r}0.15 \\
(0.0260)\end{array}$ & $\begin{array}{r}0.188 \\
(0.0289)\end{array}$ & & & \\
\hline Sample of wage earners & 31,061 & $\begin{array}{r}0.196 \\
(0.0424)\end{array}$ & $\begin{array}{r}0.199 \\
(0.0429)\end{array}$ & $\begin{array}{r}0.259 \\
(0.0499)\end{array}$ & $\begin{array}{r}0.0147 \\
(0.00729)\end{array}$ & $\begin{array}{r}0.0172 \\
(0.00737)\end{array}$ & $\begin{array}{r}0.0270 \\
(0.00850)\end{array}$ \\
\hline \multicolumn{8}{|c|}{$\begin{array}{l}\text { ment : Individuals Aged } 12 \text { to } 24 \text { in } 1974 \\
\text { uals Ages } 12 \text { to } 17 \text { in 1974) }\end{array}$} \\
\hline Whole sample & 78,488 & $\begin{array}{r}0.0093 \\
(0.0260)\end{array}$ & $\begin{array}{r}0.0176 \\
(0.0271)\end{array}$ & $\begin{array}{r}0.0075 \\
(0.0297)\end{array}$ & & & \\
\hline Sample of wage earners & 30,225 & $\begin{array}{r}0.012 \\
(0.0474)\end{array}$ & $\begin{array}{r}0.024 \\
(0.0481)\end{array}$ & $\begin{array}{r}0.079 \\
(0.0555)\end{array}$ & $\begin{array}{r}0.0031 \\
(0.00798)\end{array}$ & $\begin{array}{r}0.00399 \\
(0.00809)\end{array}$ & $\begin{array}{r}0.0144 \\
(0.00915)\end{array}$ \\
\hline
\end{tabular}

Control variables:

Year of birth*enrollment rate in 1971

No Yes Yes No $\quad$ Yes $\quad$ Yes

Year of birth* water and sanitation program

No No Y Y

Notes: All specifications include region of birth, year of birth dummies and interactions between the year of birth dummies and the number of children in the region of birth (in 1971). The numbers of observations refer to the specification in columns 1 and 4 .

Standard errors are in parentheses. 
TABLE 5 -- EFFECT OF THE PROGRAM ON EDUCATION AND WAGES: COEFFICIENTS OF THE INTERACTIONS BETWEEN DUMMIES INDICATING AGE IN 1974 AND THE NUMBER OF SCHOOLS PER 1000 CHILDREN IN REGION OF BIRTH

\begin{tabular}{|c|c|c|c|c|c|c|c|c|c|}
\hline \multirow[b]{3}{*}{ Age in 1974} & \multicolumn{6}{|c|}{ Dependent variable: years of education } & \multicolumn{3}{|c|}{ Dependent variable: $\log$ (hourly wage) } \\
\hline & \multicolumn{3}{|c|}{ Whole sample } & \multicolumn{3}{|c|}{ Sample of wage earners } & \multirow[b]{2}{*}{$(7)$} & \multirow[b]{2}{*}{$(8)$} & \multirow[b]{2}{*}{$(9)$} \\
\hline & $(1)$ & $(2)$ & $(3)$ & $(4)$ & $(5)$ & $(6)$ & & & \\
\hline 12 & $\begin{array}{l}-0.035 \\
(0.047)\end{array}$ & $\begin{array}{l}-0.025 \\
(0.048)\end{array}$ & $\begin{array}{r}0.002 \\
(0.054)\end{array}$ & $\begin{array}{r}-0.040 \\
(0.077)\end{array}$ & $\begin{array}{r}-0.010 \\
(0.078)\end{array}$ & $\begin{array}{r}0.009 \\
(0.091)\end{array}$ & $\begin{array}{r}0.016 \\
(0.013)\end{array}$ & $\begin{array}{r}0.019 \\
(0.013)\end{array}$ & $\begin{array}{r}0.027 \\
(0.015)\end{array}$ \\
\hline 11 & $\begin{array}{r}0.011 \\
(0.046)\end{array}$ & $\begin{array}{r}0.025 \\
(0.047)\end{array}$ & $\begin{array}{r}0.018 \\
(0.051)\end{array}$ & $\begin{array}{r}0.008 \\
(0.073)\end{array}$ & $\begin{array}{r}0.014 \\
(0.074)\end{array}$ & $\begin{array}{r}-0.003 \\
(0.083)\end{array}$ & $\begin{array}{r}-0.014 \\
(0.012)\end{array}$ & $\begin{array}{r}-0.013 \\
(0.013)\end{array}$ & $\begin{array}{r}-0.009 \\
(0.014)\end{array}$ \\
\hline 10 & $\begin{array}{r}0.059 \\
(0.047)\end{array}$ & $\begin{array}{r}0.049 \\
(0.049)\end{array}$ & $\begin{array}{r}0.078 \\
(0.054)\end{array}$ & $\begin{array}{r}0.10 \\
(0.075)\end{array}$ & $\begin{array}{r}0.092 \\
(0.076)\end{array}$ & $\begin{array}{r}0.13 \\
(0.090)\end{array}$ & $\begin{array}{r}0.0036 \\
(0.013)\end{array}$ & $\begin{array}{r}0.0042 \\
(0.013)\end{array}$ & $\begin{array}{c}0.0059 \\
(0.015)\end{array}$ \\
\hline 9 & $\begin{array}{r}0.14 \\
(0.039)\end{array}$ & $\begin{array}{r}0.14 \\
(0.041)\end{array}$ & $\begin{array}{r}0.15 \\
(0.044)\end{array}$ & $\begin{array}{r}0.067 \\
(0.065)\end{array}$ & $\begin{array}{r}0.063 \\
(0.066)\end{array}$ & $\begin{array}{r}0.17 \\
(0.077)\end{array}$ & $\begin{array}{c}0.0095 \\
(0.011)\end{array}$ & $\begin{array}{r}0.010 \\
(0.011)\end{array}$ & $\begin{array}{r}0.018 \\
(0.013)\end{array}$ \\
\hline 8 & $\begin{array}{r}0.088 \\
(0.049)\end{array}$ & $\begin{array}{r}0.11 \\
(0.050)\end{array}$ & $\begin{array}{r}0.11 \\
(0.054)\end{array}$ & $\begin{array}{r}0.19 \\
(0.078)\end{array}$ & $\begin{array}{r}0.20 \\
(0.079)\end{array}$ & $\begin{array}{r}0.28 \\
(0.089)\end{array}$ & $\begin{array}{r}0.019 \\
(0.013)\end{array}$ & $\begin{array}{r}0.021 \\
(0.013)\end{array}$ & $\begin{array}{r}0.027 \\
(0.015)\end{array}$ \\
\hline 7 & $\begin{array}{r}0.12 \\
(0.044)\end{array}$ & $\begin{array}{r}0.14 \\
(0.046)\end{array}$ & $\begin{array}{r}0.16 \\
(0.051)\end{array}$ & $\begin{array}{r}0.11 \\
(0.072)\end{array}$ & $\begin{array}{r}0.13 \\
(0.073)\end{array}$ & $\begin{array}{r}0.16 \\
(0.084)\end{array}$ & $\begin{array}{r}-0.0095 \\
(0.012)\end{array}$ & $\begin{array}{r}-0.0049 \\
(0.012)\end{array}$ & $\begin{array}{r}0.0066 \\
(0.014)\end{array}$ \\
\hline 6 & $\begin{array}{r}0.14 \\
(0.042)\end{array}$ & $\begin{array}{r}0.17 \\
(0.044)\end{array}$ & $\begin{array}{r}0.26 \\
(0.049)\end{array}$ & $\begin{array}{r}0.23 \\
(0.070)\end{array}$ & $\begin{array}{r}0.23 \\
(0.070)\end{array}$ & $\begin{array}{r}0.32 \\
(0.084)\end{array}$ & $\begin{array}{r}0.011 \\
(0.012)\end{array}$ & $\begin{array}{r}0.013 \\
(0.012)\end{array}$ & $\begin{array}{r}0.018 \\
(0.014)\end{array}$ \\
\hline 5 & $\begin{array}{r}0.10 \\
(0.043)\end{array}$ & $\begin{array}{r}0.13 \\
(0.045)\end{array}$ & $\begin{array}{r}0.13 \\
(0.050)\end{array}$ & $\begin{array}{r}0.14 \\
(0.075)\end{array}$ & $\begin{array}{r}0.16 \\
(0.075)\end{array}$ & $\begin{array}{r}0.27 \\
(0.088)\end{array}$ & $\begin{array}{r}0.021 \\
(0.013)\end{array}$ & $\begin{array}{r}0.023 \\
(0.013)\end{array}$ & $\begin{array}{r}0.052 \\
(0.015)\end{array}$ \\
\hline 4 & $\begin{array}{r}0.11 \\
(0.039)\end{array}$ & $\begin{array}{r}0.12 \\
(0.041)\end{array}$ & $\begin{array}{r}0.18 \\
(0.046)\end{array}$ & $\begin{array}{r}0.19 \\
(0.069)\end{array}$ & $\begin{array}{r}0.19 \\
(0.069)\end{array}$ & $\begin{array}{r}0.29 \\
(0.082)\end{array}$ & $\begin{array}{r}0.019 \\
(0.012)\end{array}$ & $\begin{array}{r}0.020 \\
(0.012)\end{array}$ & $\begin{array}{r}0.038 \\
(0.014)\end{array}$ \\
\hline 3 & $\begin{array}{r}0.11 \\
(0.044)\end{array}$ & $\begin{array}{r}0.14 \\
(0.046)\end{array}$ & $\begin{array}{r}0.20 \\
(0.053)\end{array}$ & $\begin{array}{r}0.15 \\
(0.079)\end{array}$ & $\begin{array}{r}0.17 \\
(0.080)\end{array}$ & $\begin{array}{r}0.30 \\
(0.097)\end{array}$ & $\begin{array}{c}0.0079 \\
(0.013)\end{array}$ & $\begin{array}{r}0.013 \\
(0.014)\end{array}$ & $\begin{array}{r}0.027 \\
(0.016)\end{array}$ \\
\hline 2 & $\begin{array}{r}0.14 \\
(0.041)\end{array}$ & $\begin{array}{r}0.19 \\
(0.043)\end{array}$ & $\begin{array}{r}0.19 \\
(0.049)\end{array}$ & $\begin{array}{r}0.20 \\
(0.073)\end{array}$ & $\begin{array}{r}0.22 \\
(0.074)\end{array}$ & $\begin{array}{r}0.25 \\
(0.088)\end{array}$ & $\begin{array}{r}0.016 \\
(0.012)\end{array}$ & $\begin{array}{r}0.023 \\
(0.013)\end{array}$ & $\begin{array}{r}0.040 \\
(0.015)\end{array}$ \\
\hline $\begin{array}{l}\quad \text { Control variables: } \\
\text { Year of birth*enrollment rate in } 1971 \\
\text { Year of birth*water and sanitation program }\end{array}$ & $\begin{array}{l}\text { No } \\
\text { No }\end{array}$ & $\begin{array}{l}\text { Yes } \\
\text { No }\end{array}$ & $\begin{array}{l}\text { Yes } \\
\text { Yes }\end{array}$ & $\begin{array}{l}\text { No } \\
\text { No }\end{array}$ & $\begin{array}{c}\text { Yes } \\
\text { No }\end{array}$ & $\begin{array}{l}\text { Yes } \\
\text { Yes }\end{array}$ & $\begin{array}{l}\text { No } \\
\text { No }\end{array}$ & $\begin{array}{l}\text { Yes } \\
\text { No }\end{array}$ & $\begin{array}{l}\text { Yes } \\
\text { Yes }\end{array}$ \\
\hline $\begin{array}{l}\text { F-statistic } \\
\text { R-squared } \\
\text { Obervations }\end{array}$ & $\begin{array}{r}4.03 \\
0.19 \\
152,989\end{array}$ & $\begin{array}{r}5.18 \\
0.19 \\
152,495\end{array}$ & $\begin{array}{r}6.15 \\
0.17 \\
143,107\end{array}$ & $\begin{array}{r}2.70 \\
0.14 \\
60,633\end{array}$ & $\begin{array}{r}2.74 \\
0.14 \\
60,466\end{array}$ & $\begin{array}{r}4.38 \\
0.13 \\
55,144\end{array}$ & $\begin{array}{r}1.13 \\
0.14 \\
60,633\end{array}$ & $\begin{array}{r}1.29 \\
0.15 \\
60,466\end{array}$ & $\begin{array}{r}2.05 \\
0.13 \\
55,144\end{array}$ \\
\hline
\end{tabular}

Notes: All specifications include region of birth and year of birth dummies and year of birth dummies interacted with population in 1971

Standard errors are in parentheses. 'The F-statistics test the hypothesis that the coefficients of the interaction between the year of birth dummies and the program intensity in the region of birth are jointly zero.

The control group is the group of people who were 13 to 24 in 1974. 
TABLE 6 -- EFFECT OF EDUCATION ON LABOR MARKET OUTCOMES. OLS AND 2SLS ESTIMATES

\begin{tabular}{|c|c|c|c|c|c|}
\hline Method & Instrument & $(1)$ & (2) & (3) & $(4)$ \\
\hline \multicolumn{6}{|c|}{ PANEL A: Sample of Individuals Who Work for a Wage } \\
\hline \multicolumn{6}{|c|}{ PANEL A1: Dependent variable: $\log$ (hourly wage) } \\
\hline OLS & & $\begin{array}{r}0.0776 \\
(0.000620)\end{array}$ & $\begin{array}{r}0.0777 \\
(0.000621)\end{array}$ & $\begin{array}{r}0.0767 \\
(0.000646)\end{array}$ & \\
\hline 2SLS & Year of birth dummies* program intensity in region of birth & $\begin{array}{r}0.0675 \\
(0.0280) \\
{[0.96]}\end{array}$ & $\begin{array}{r}0.0809 \\
(0.0272) \\
{[0.9]}\end{array}$ & $\begin{array}{r}0.106 \\
(0.0222) \\
{[0.93]}\end{array}$ & $\begin{array}{r}0.0908 \\
(0.0541) \\
{[0.9]}\end{array}$ \\
\hline 2SLS & (Aged 2-6 in 1974)*program intensity in region of birth & $\begin{array}{r}0.0752 \\
(0.0338)\end{array}$ & $\begin{array}{r}0.0862 \\
(0.0336)\end{array}$ & $\begin{array}{r}0.104 \\
(0.0304)\end{array}$ & \\
\hline
\end{tabular}

\section{PANEL A2: Dependent variable: $\log$ (monthly earnings)}

OLS

$\begin{array}{lrr}0.0698 & 0.0698 & 0.0689\end{array}$

2SLS Year of birth dummies* program intensity in region of birth

$(0.000601) \quad(0.000602) \quad(0.000628)$

$\begin{array}{rrrr}0.0756 & 0.0925 & 0.0913 & 0.134 \\ (0.0280) & (0.0278) & (0.0219) & (0.0631) \\ {[0.73]} & {[0.63]} & {[0.58]} & {[0.7]}\end{array}$

PANEL B: Complete Sample

PANEL B1: Dependent variable: participation in the wage sector OLS

$\begin{array}{rrr}0.0328 & 0.0327 & 0.0337 \\ (0.00311) & (0.000311) & (0.000319) \\ 0.101 & 0.118 & 0.0892 \\ (0.0210) & (0.0197) & (0.0162) \\ {[0.66]} & {[0.93]} & {[1.12]}\end{array}$

PANEL B2: Dependent variable: $\log (m o n t h l y ~ e a r n i n g s)$, imputed for self-employed individuals OLS $0.0539 \quad 0.0539$ 0.0539 $(0.000354) \quad(0.000354)$ $(0.000355)$

2SLS Year of birth dummies* program intensity in region of birth

$\begin{array}{rrr}0.0509 & 0.0745 & 0.0346 \\ (0.0157) & (0.0136) & (0.0138) \\ {[0.68]} & {[0.58]} & {[1.16]}\end{array}$

Control variables:

Year of birth*enrollment rate in 1971

\begin{tabular}{lccc} 
No & Yes & Yes & Yes \\
No & No & Yes & No \\
No & No & No & Yes \\
\hline
\end{tabular}

Propensity score, propensity score squared

Notes: Year of birth dummies, region of birth dummies and the interactions between year of birth dummies and the number of children in the region of birth in 1971 are included in the regressions. Standard errors are in parenthesis. F-statistics of the test of overidentification restrictions are in squared brackets. 
TABLE 7 -- PROGRAM EFFECT AND RETURNS TO EDUCATION BY CATEGORIES OF REGION OF BIRTH

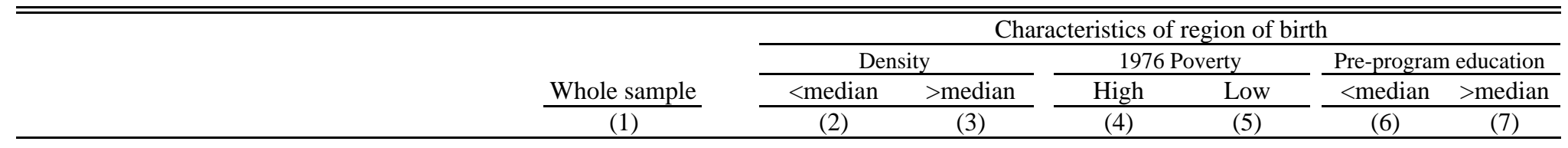

\section{PANEL A: Effect of the Program on Education.}

Dependent variable: Years of education. Sample: individuals ages 2 to 6 or 12 to 17 in 1974

$\begin{array}{lrrrrrrr}\text { Interaction } & 0.15 & 0.19 & -0.014 & 0.13 & 0.083 & 0.14 & 0.13 \\ (2-6 \text { in 1974)*program intensity in region of birth } & (0.026) & (0.035) & (0.048) & (0.058) & (0.035) & (0.040) & (0.036)\end{array}$

PANEL B: Effect of the Program on Wages.

Dependent variable: $\log ($ hourly wage). Sample: individuals ages 2 to 6 or 12 to 17 in 1974 (wage earners)

\begin{tabular}{|c|c|c|c|c|c|c|}
\hline $\begin{array}{l}\text { Interaction } \\
(2-6 \text { in } 1974) * \text { program intensity in region of birth }\end{array}$ & $\begin{array}{r}0.017 \\
(0.0074)\end{array}$ & $\begin{array}{r}0.032 \\
(0.011)\end{array}$ & $\begin{array}{r}-0.00084 \\
(0.012)\end{array}$ & $\begin{array}{r}0.051 \\
(0.017)\end{array}$ & $\begin{array}{r}-0.00083 \\
(0.0094)\end{array}$ & $\begin{array}{r}0.028 \\
(0.013)\end{array}$ \\
\hline
\end{tabular}

\section{PANEL C: Returns to Education.}

Dependent variable: log (hourly wage). Sample: wage earners

\begin{tabular}{|c|c|c|c|c|c|c|c|}
\hline Years of education & $\begin{array}{r}0.078 \\
(0.00062) \\
{[0.9]}\end{array}$ & $\begin{array}{r}0.11 \\
(0.026) \\
{[0.86]}\end{array}$ & $\begin{array}{l}\text { No } \\
\text { First stage }\end{array}$ & $\begin{array}{r}0.10 \\
(0.028) \\
{[0.88]}\end{array}$ & $\begin{array}{l}\text { No } \\
\text { First stage }\end{array}$ & $\begin{array}{r}0.12 \\
(0.032) \\
{[0.72]}\end{array}$ & $\begin{array}{c}0.029 \\
(0.052) \\
{[0.83]}\end{array}$ \\
\hline
\end{tabular}

Notes: Region of birth dummies, year of birth dummies, and interactions of year of birth dummies and the number of children and the enrollment rate in

the region in 1971 are included in the regressions.

The median density (the density for the region of birth for the median person in the weighted sample) is 308 habitants per square kilometer.

The high poverty provinces are the provinces where the proportion of people consuming less than 1,500 Rp per capita is larger than the national average (11.3\%) for rural regions. (in the 1976 SUSENAS). I define as "high poverty" districts the rural districts in these provinces, which are: Lampung, Central Java, Jogyakarta, East Java, East Nusa Tenggara,

Central Sulawesi, South Sulawesi, Southeast Sulawesi, Maluku, Irian Jaya. Source: World Bank (1979).

The pre-program education is the average education in the region of birth for people born in 1962 or before. The median is 3.18 years.

Standard errors in parenthesis, F-statistics of the overidentification test in squared brackets. 


\begin{tabular}{llccccc}
\hline \hline & \multicolumn{4}{c}{ Deadweight loss coefficient } \\
\cline { 2 - 3 } \cline { 5 - 6 } & \multicolumn{2}{c}{0.2} & $(2)$ & $(3)$ & $(4)$ \\
\hline
\end{tabular}

\section{PANEL A: Results}

Control for Year of birth*enrollment rate

No

Yes

No

Yes

First year where benefit $>$ costs (discount rate $=5 \%$ )

In annual value:

$1996 \quad 1996 \quad 1997 \quad 1997$

In discounted sum

2005

2002

2009

2005

Discounted sum of net benefits in 2050 (g after 1997=5\%, discount rate 5\%)

In million 1990 US\$

As a fraction of Indonesia's GDP in 1973

$13,025 \quad 13,096$

$11,340 \quad 18,807$

$0.30 \quad 0.36$

$0.31 \quad 0.52$

Divided by initial costs

24.1

24.2

21.0

35.0

Discounted sum of net benefits in 2050 (g after 1997=2\%, discount rate 5\%)

In milllion 1990 US\$

$6,691 \quad 11,589$

$5,008 \quad 9,905$

As a fraction of Indonesia's GDP in 1973

0.18

0.32

0.14

0.27

Divided by initial costs

$12.4 \quad 21.4$

9.26

18.3

Discounted sum of net benefits in 2050 ( $\mathrm{g}$ from $1973=\mathbf{2 \%}$, discount rate $5 \%$ )

In million 1990 US\$

As a fraction of Indonesia's GDP in 1973

Divided by initial costs

Internal rate of return

g after $1997=5 \%$

g after $1997=2 \%$

$\mathrm{g}$ from $1973=2 \%$

\section{PANEL B: Assumptions and Parameters}

Population growth rate after 1997

$-631.6$

$-0.017$

1200

0.033

$-1.16$

2.22

$-2315$

$-0.063$

$-4.28$

$-483$

$-0.013$

$-0.89$

Yearly teacher salary in 1973 (1990 US \$)

Yearly teachers salary in 1995 (1990 US \$)

Total recurrent costs/teacher salary

0.102

0.088

0.118

0.0895

0.105

0.0443

0.059

0.0750

0.0326

0.0915

0.0467

0.015

363

2,467

1.25

Total cost of construction (million 1990 US \$)

522

Number of school constructed

61,800

Life time of the schools (years)

20

Share of labor income in GDP

0.7

Note: The estimates underlying these calculations are taken from table 5 (columns 7 and 8).

Program effect has been set to 0 for children aged 7 or older in 1974.

The internal rate of return is the interest rate such that the net present value of the project at infinity is 0 . 
TABLE A1 -- UNRESTRICTED ESTIMATES OF PROGRAM EFFECT: COEFFICIENTS OF THE INTERACTION BETWEEN AGE IN 1974 AND THE NUMBER OF SCHOOLS PER 1000 CHILDREN BUILT IN THE REGION OF BIRTH

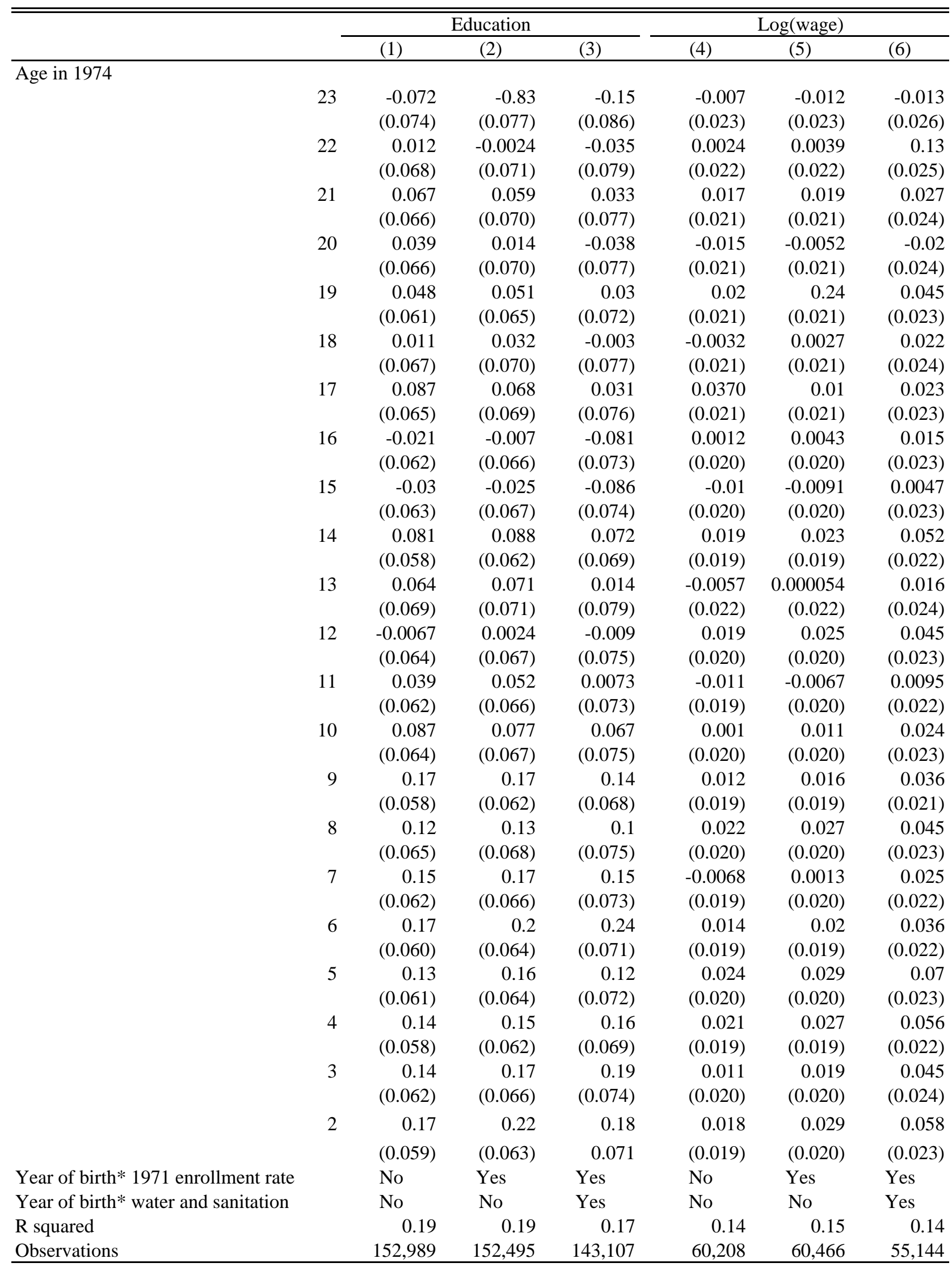

Notes: Standard errors are in parentheses. All regressions include year of birth dummies, region of birth dummies, and year of birth dummies interacted with number of children in 1971. The omitted group is the group aged 24 in 1974. 